\title{
Identification of Major Cell Classes in the Developing Mammalian Nervous System ${ }^{1}$
}

\author{
S. HOCKFIELD ${ }^{2}$ AND R. D. G. MCKAY ${ }^{3}$ \\ Cold Spring Harbor Laboratory, Cold Spring Harbor, New York 11724
}

\begin{abstract}
A major difficulty in studying early developmental processes and testing hypotheses of possible cellular mechanisms of development has been the inability to reproducibly identify specific cell types. We have generated monocional antibodies that distinguish among major cell types present during mammalian neurogenesis. These antibodies have been used to analyze the development of celiular organization in the early nervous system. Monoclonal antibody Rat401 identifies a transient radial glial cell in the embryonic rat central nervous system (CNS) that is temporally and spatially suited to guide neuronal migration. Rat-401 also identifies a peripheral non-neuronal cell that may establish axon routes from the CNS to the periphery. Monoclonal antibody Rat-202 recognizes an antigen present in early axons, their growth cones, and filopodia, and has allowed us to follow early axons and observe the structures they contact. Two other antibodies that recognize axons demonstrate antigenically distinct phases in axon development. In addition, we report a marker for another cell class present in the developing nervous system, the endothelial cells that give rise to the CNS vasculature.
\end{abstract}

Molecular techniques have confirmed and extended earlier anatornical and physiological studies showing that the adult vertebrate central nervous system (CNS) is composed of a large number of different cell types. This large number of cell types is derived during a short period of embryonic development from a small number (approximately $10^{4}$; unpublished observations) of morphologically homogeneous neuroepithelial cells at embryonic day 10 in the rat. In response to a mesodermal signal (Spemann, 1936) the early neuroectodermal cells proliferate and differentiate to give rise to the adult brain which contains a morphologically heterogeneous population of greater than $10^{9}$ neurons and glial cells. Particular developmental features of the early neural tube, such as the birthdate of

Received March 6, 1985; Revised June 27, 1985:

Accepted July 2, 1985

' We would like to thank Elizabeth Waldvogel and Carmelita Bautista for their continued excellent technical assistance, Dr. B. Friedman for discussions of the manuscript, Mike Ockler for graphics, and Marlene Rubino for secretarial help. We thank Dr. L. Eng, Dr. B. Pruss and Dr. S. Blose for their generosity in supplying antibodies to, respectively, glial fibrillary acidic protein, intermediate filaments, and vimentin. National Institutes of Health Grants NS 18040 (S. H.) and NS 17556 (R. D. G. M.) and National Science Foundation Grant BNS 84-19240 (S. H.) supported this work.

${ }^{2}$ To whom correspondence should be addressed, at her present address: Section of Neuroanatomy, Yale University School of Medicine, 333 Cedar St., New Haven, CN 06510

${ }^{3}$ Present address: Whitaker College and Department of Biology, E25-435, Massachusetts Institute of Technology, Cambridge, MA 02139. neurons (Sidman, 1970) and the guiding role of radial glial cells (Rakic, 1971), are thought to have important consequences for the synaptic organization of the adult brain. Several recent studies have used cell type-specific markers to study cellular differentiation in the peripheral nervous system (PNS) (Le Douarain, 1980; Barald, 1982; Vincent and Thiery, 1984). Fewer cell type-specific markers have been described in the vertebrate CNS. Recent progress in using hybridoma technology to identify subsets of adult (Hawkes et al., 1982; McKay and Hockfield, 1982; Sternberger et al., 1982) and embryonic (Levitt, 1984) vertebrate neurons and to study glial cell origins (Raff et al., 1983) suggested to us that a similar strategy might provide reagents to identify cell types in the developing vertebrate CNS. These reagents could then be used to study cellular mechanisms of development in the early neural tube which give rise to the differentiated adult vertebrate brain.

In this paper we describe a set of reagents which identify major structures and developmental periods in the embryonic nervous system of the rat. We have used three reagents to describe the cellular organization of the embryonic nervous system and to study its development. These reagents have enabled us to identify three classes of cellular elements in the developing mammalian nervous system: axons; radial glia and early Schwann-like cells; and early endothelial cells. We have used three monoclonal antibodies to study axonal development and have shown that each antibody recognizes antigens that are expressed at distinct stages in development. One antibody labels early-growing axons and their growth cones and filopodia, enabling us to follow axons as they grow from the CNS to the periphery, whereas the two other antibodies label axons at later stages in their devclopment. Another monoclonal antibody recognizes the early radial glial cells but does not recognize cells in the adult CNS. The transient expression of the antigen recognized by this antibody correlates with the period of neuronal proliferation and migration. This antibody also identifies a nonneuronal cell that appears to precede and predict axon pathways from the CNS into the periphery. We also describe here a marker for cells that give rise to the CNS vasculature.

\section{Materials and Methods}

In order to obtain markers for the major cell classes in the devcloping neural tube we generated monoclonal antibodies to fixed spinal cord from embryonic day 15 (E15) rats. Timed pregnant female rats were obtained from Taconic Animal Supply Co. and housed until the appropriate gestational age. Uteri were dissected from pregnant animals into ice-cold phosphate buffer $(\mathrm{pH} 7.4)$, individual embryos were removed, and the spinal cord was dissected free of other tissue into fixative (4\% paraformaldehyde in $0.1 \mathrm{M}$ phosphate buffer). We followed an immunization and fusion protocol that has been described previously (McKay and Hockfield, 1982). Briefly, $\mathrm{BALB} / \mathrm{C}$ mice received two intraperitoneal immunizations with fixed tissue homogenized in saline and suspended in an equal volume of Freund's complete adjuvant and a final intravenous boost of unfixed tissue without adjuvant. Spleen cells from immunized mice were fused with NS-1 myeloma cells, and resulting hybrid cell lines were screened immunohistochemically 
on $100-\mu \mathrm{m}$-thick Vibratome sections of $4 \%$ paraformaldehyde-fixed $\mathrm{E} 15$ rats. Lines producing antibodies of interest were cloned in soft agar or by limiting dilution, and antibody subclass was determined by the Ouchterlony method (Ouchterlony and Nilsson, 1978).

Immunohistochemistry. Tissue for immunohistochemistry was fixed either by intravascular perfusion or by immersion. All postnatal material was fixed by intravascular perfusion (under ether anesthesia) with $4 \%$ paraformaldehyde at $\mathrm{pH} 7.4$ for light microscopy or with either $4 \%$ paraformaldehyde at $\mathrm{pH} 10.0$ or $4 \%$ paraformaldehyde, $0.1 \%$ giutaraldehyde at $\mathrm{pH} 7.4$ for electron microscopy. The CNS was dissected out and stored in $0.1 \mathrm{M}$ phosphate buffer $(\mathrm{pH} 7.4)$ with $0.1 \%$ sodium azide. For prenatal material, pregnant females were ether anesthetized, uteri were dissected into cold $0.1 \mathrm{M}$ phosphate buffer, and the females were killed by cervical dislocation. Embryos were dissected individually into Sylgard-coated Petri dishes and pinned in place. Intravascular perfusion was performed by opening the skin of the thoracic cavity, nicking the right atrium with a fine forceps, and placing a 25 gauge needle into the left ventricle. One to $5 \mathrm{ml}$ of fixative (as above) were injected into the heart. The embryos were placed in a vial containing the same fixative for $4 \mathrm{hr}$ and then stored in phosphate buffer. E12 to term embryos were fixed by perfusion (using a 30 gauge needle for $E 12$ embryos); E10 and E11 embryos were fixed by immersion in fixative. E13 and older animals were sectioned at 50 to $100 \mu \mathrm{m}$ on a Vibratome without additional support. E10 to E12 embryos were embedded in $15 \%$ gelatin before sectioning.

Immunohistochemical reactions were performed on free-floating sections by sequential incubations in monoclonal antibody as full-strength supernatant (12 to $20 \mathrm{hr}$ ); horseradish peroxidase (HRP)-conjugated goat anti-mouse antibody at a dilution of 1:100 in tissue culture medium with $10 \%$ serum; and $3,3^{\prime}$-diaminobenzidine (DAR; $0.025 \%$ ) with $\mathrm{H}_{2} \mathrm{O}_{2}(0.002 \%$ ). Peroxidase-conjugated lectins (Sigma Chemical Co.) were used at serial dilutions in the same manner with the omission of the peroxidase-conjugated goat antimouse antibody. For light microscopy, $2 \%$ Triton $\times 100$ was included in both antibody solutions. For electron microscopy sections carried through this procedure (without Triton X-100) were post-fixed in $2 \% \mathrm{O}_{5} \mathrm{O}_{4}$, embedded in Epori/Araldite belween plastic coverslips, and cut at $1 \mu \mathrm{rm}$ and $0.12 \mu \mathrm{m}$ for correlative light and electron microscopy. For high resolution light microscopy, sections (Triton-treated) were embedded in plastic as for electron microscopy and sectioned at $2 \mu \mathrm{m}$.

Immunoblots. The apparent molecular weights of antigens recognized by antibodies were determined using the method of Towbin et al. (1979). Proteins were extracted from unfixed tissue with sodium dodecyl sulfate (SDS) and $\beta$-mercaptoethanol and run on an SDS-polyacrylamide gel. The proteins were electroblotted onto nitrocellulose paper which was then exposed to primary (1 hr) and secondary (1 hr) antibodies. HRP was visualized with 4-chloronaphthol.

\section{Results}

Because we wished to study early events in neuronal differentiation including axonal outgrowth and the proliferation of cells in the neural epithelium, we raised monoclonal antibodies against the E15 neural tube. At this time, differentiated neurons coexist with rapidly dividing neuroepithelial cells. The immunization and screening strategies we chose were similar to those we have employed in earlier studies of invertebrate and vertebrate nervous systems (Zipser and McKay, 1981; McKay and Hockfield, 1982). Mice were immunized with paraformaldehyde-fixed E15 spinal cord and screened for antibodies of interest by an immunohistochemical assay on fixed Vibratome sections of E15 embryos. As additional potential probes for antigenic diversity, we also screened several peroxidase-conjugated lectins for their ability to identify specific cellular structures in the E15 neural tube.

\section{Major cellular features of the neural tube}

Non-neuronal cells. In Figure 1 we show the distribution of three major cell classes we have identified in the E15 neural tube. Among the antibodies we generated was Rat-401 (Fig. $1 B$ ), a monoclonal antibody which binds to an antigen transiently expressed in a subset of CNS cells during development and in non-neuronal cells in the PNS

Axonal processes. We also generated antibodies which recognize axonal processes (Fig. 1A) and have used such antibodies to study the relationships between axons and other cell types. The distribution of the antigenic determinants recognized by one of these antibodies (Rat-202) includes most, and perhaps all, of the central and peripheral axons in both embryo and adult. Antibodies which we have previously shown to bind to adult axonal antigens (McKay and Hockfield, 1982) also recognized axons, but not at the earliest stages of their development. In the present report we show that these antibodies which were raised against adult cat spinal cord appear at distinct times in different axon tracts and may mark different stages in axon maturation (see Fig. 13).

Endothelial cells. We also report here on the appearance in the embryonic neural tube of another major class of proliferating cells which give rise to the vascular system (Fig. 1C). These endothelial cells are specifically identified by a lectin-purified from Banderia simplicifolia (BAND).

\section{Monoclonal antibody Rat-401 recognizes radial glial cells}

In the developing neural tube, monoclonal antibody Rat-401 recognizes cells having a morphology which matches that described for radial glial cells (Ramón y Cajal, 1929). On immunoblots of SDSpolyacrylamide gels Rat-401 binds to a doublet of 200 kilodaltons (kd) in apparent molecular weight (Fig. 2) and, therefore, recognizes a molecular species different from vimentin $(57 \mathrm{kd})$ and glial fibrillary acidic protein (GFAP) (52 kd), two other markers for radial glia in, respectively, the rodent (Dahl et al., 1981; Tapscott et al., 1981) and primate (Levitt and Rakic, 1980). Each of these three markers of radial glial cells has a distinct distribution in the adult spinal cord. Rat-401 does not recognize any cellular element in the adult CNS (Fig. 2A), whereas anti-vimentin antibodies recognize ependymal cells (Fig. $3 B$ ) and anti-GFAP antibodies recognize glial cells (Fig. $3 C)$.

Rat-401-positive cells are found throughout the developing neural tube and have several morphological features that match those of radial glia. First, Rat-401 cells span the neural tube, extending from ventricular to pial surfaces (Fig. $1 B$ ). Second, immunoelectron microscopic examination of the ventricular surface has shown that many Rat-401-positive cells contain mitotic figures (see Fig. 6B), showing that the antigen is expressed in proliferating cells. Third, at the pial surface, Rat-401-positive processes terminate in expansions, or end-feet (Fig. 4, $A$ and $B$ ). These end-feet in the spirlal cord at E15 form an almost continuous sheet along the ventral pial surface (Fig. $4 D$ ) but form a discontinuous sheet along the dorsal surface (Fig. 4C).

Rat-401 staining is first seen in the developing neural tube at E11, after the neural tube has closed. Initially, at the light microscopic level, small, punctate, antibody-positive profiles appear on the pial surface (Fig. 5, $A$ and $B$ ). Electron microscopic immunocytochemistry has shown that, at E11, the Rat-401 antigens do not uniformly fill cell processes at the pial surface but are concentrated in small areas against the cell membrane (Fig. 5, $C$ and $D$ ). In the embryonic spinal cord development proceeds along a rostrocaudal gradient with the rostral cervical segments being the most advanced (Nornes and Das, 1974). This allows subtle temporal developmental differences to be seen within an animal along its rostrocaudal axis. At late E11, the lcss advanced, more caudal levels of the neural tube show the punctate staining with Rat-401 described above. At slightly more advanced stages of development, seen more rostrally at E11 and in the most caudal sections from an E12 animal, Rat-401 antigens are no longer restricted to the pial surface but extend throughout the neuroepithelial cells, and many cells in the neural tube are Rat-401 positive. In 50- $\mu \mathrm{m}$-thick Vibratome sections and in $2-\mu \mathrm{m}$-thick Epon sections from rostral levels of $\mathrm{E} 11$ and caudal levels of E12 animals, most, and perhaps all, cells appear to be Rat-401 positive (see Fig. 12A). Our studies on dissociated cells have shown that 98 to $100 \%$ of E11 neural tube cells are Rat-401 positive (Frederikson et al., 1985). By E13, Rat-401-positive profiles assume a more slender, radial appearance, and antibody-negative cells become apparent. Antibody-negative cells are seen clear in the ventral portion of the developing spinal cord where postmitotic 

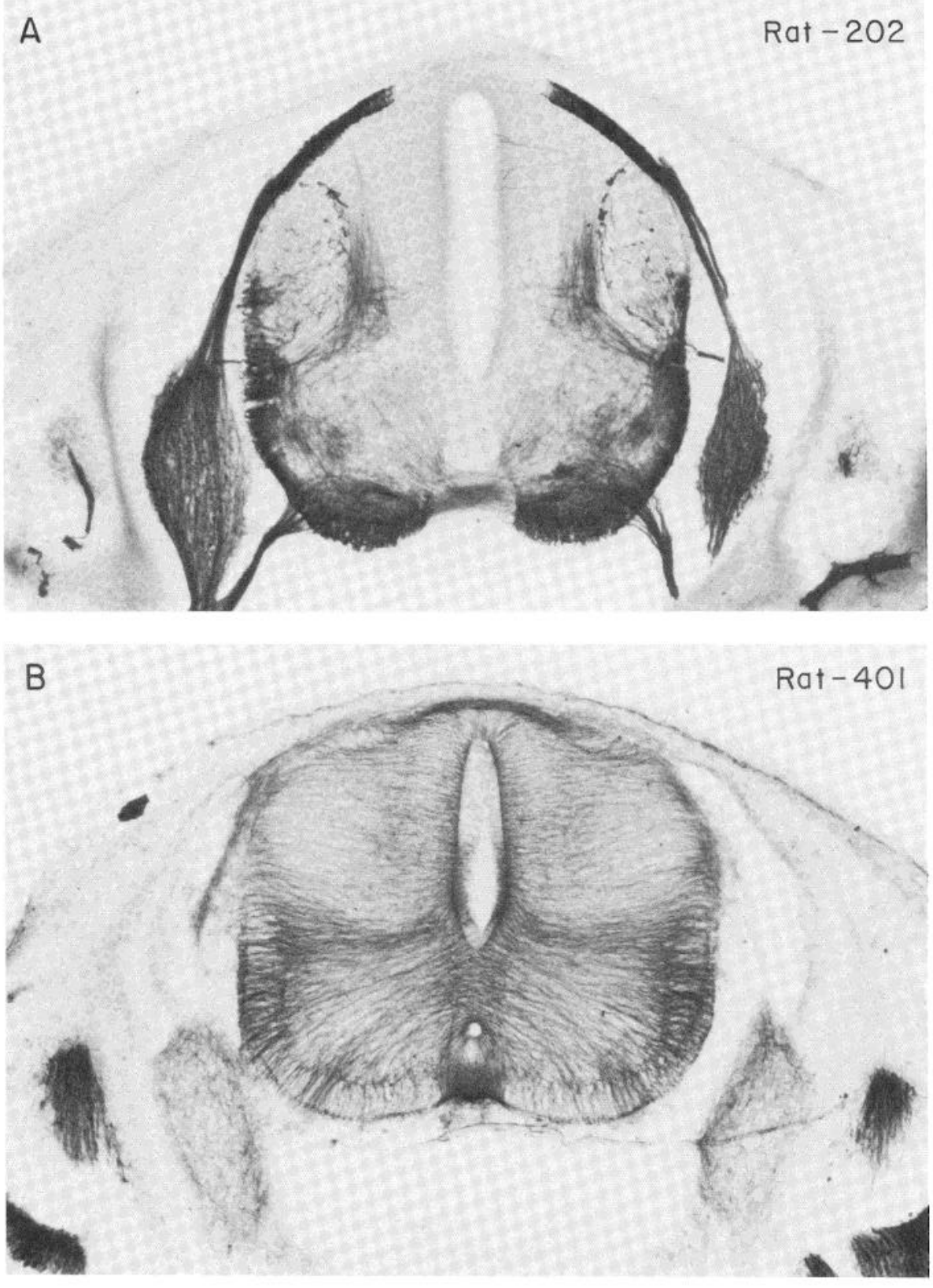

Figure 1. Markers that differentiate among prevalent cell types in developing CNS illustrated in transverse, $100-\mu \mathrm{m}$ thick sections of $\mathrm{E} 15$ rats. $A$, Monoclonal antibody Rat-202 stains axons in the developing spinal cord and periphery. $B$, Monoclonal antibody Rat-401 stains radial glia in the CNS, non-neuronal cells in nerve routes, and developing muscle cells. C, Lectins from Bandeiria simplicofolia (Band) stain developing blood vessels. Scale bar $=1 \mathrm{~mm}$.

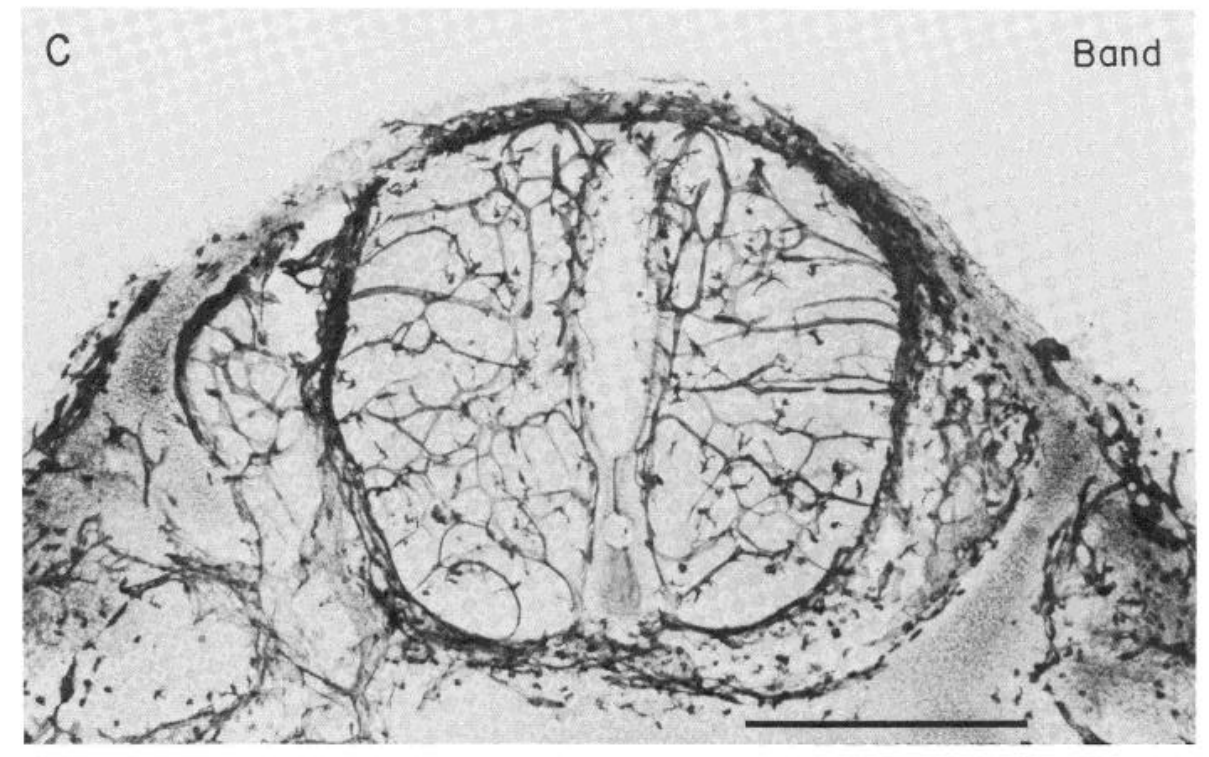


A

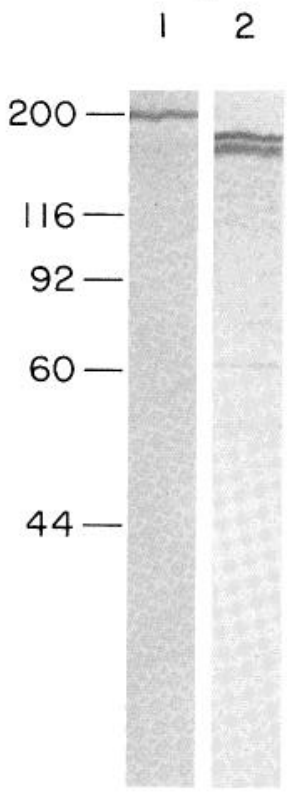

4

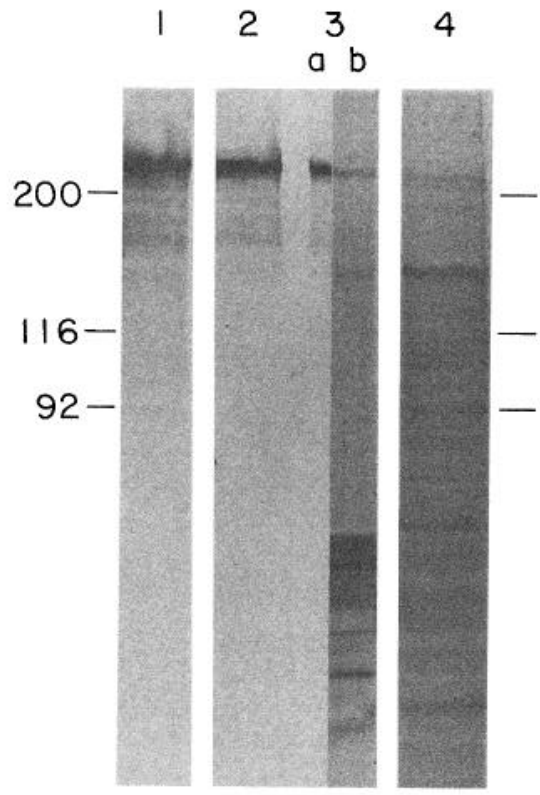

Figure 2. Immunoblots of monoclonal antibodies Rat-401, Rat-202, Cat101, and Cat-201. A, Lane 1: A prominent 200-kd band is seen on immunoblots with the monoclonal antibody Rat-401. Lane 2: Two strong bands of lower molecular weight $\left(M_{\mathrm{r}}=180,000\right)$ are the major antigens detected with the antibody Rat-202. B, Lanes 1 and 2: The monoclonal antibodies Cat-101 and Cat-201 recognize an antigen which migrates more slowly than the myosin marker (200 kd). Lanes 3, $a$ and b; A gel track divided after transfer to nitrocellulose paper and reacted with Cat-201 and a monoclonal antibody against intermediate filament proteins (Pruss et al., 1981). The band recognized by Cat-201 is coincident with the largest protein of the neurofilament triplet. Lane 4: An amido black-stained parallel track also shows an abundant protein that co-migrates with the antigen recognized by Cat-101 and Cat201.

neurons begin to populate the future ventral horn (Fig. 6A). At E13, Rat-401-positive cells are also found in several locations in the periphery (Fig. 6, $C$ to $F$ ) and are discussed further below.

Rat-401 antigens are not present in the adult CNS, unlike vimentin and GFAP (Fig. 3). Different areas of the CNS lose Rat-401 immunoreactivity over different time courses. In the areas we have examined, the loss of antigen corresponds to the end of the period of neuronal proliferation and migration. In the spinal cord (Fig. 7, D to F) Rat-401 staining begins to decrease at E19. At birth there are few positive profiles and by postnatal day 6 (P6) there are none. In contrast, in the cerebellum (Fig. 7, $A$ to $C$ ) at $\mathrm{P} 2$ many cells are Rat401 positive. At P12 the staining begins to diminish, and by P21 the cerebellum is free of Rat-401-positive profiles. Other studies have shown that the peak of neuronal proliferation and migration is past at E19 in the spinal cord (Nornes and Das, 1974) and at P21 in the cerebellum (Altman, 1972).

\section{Monoclonal antibody Rat-202 recognizes differentiated neurons and early axons}

Antibody Rat-202 recognizes neurons and axons in the E15 neural tube (Fig. $1 A$ ) and in the adult CNS. On immunoblots of SDSpolyacrylamide gels Rat-202 binds to a $180-\mathrm{kd}$ species that does not co-migrate with any of the three major neurofilament proteins (Fig. 2) which have been recognized by antisera and monoclonal antibodies (Pruss et al., 1981; Shaw and Weber, 1982; Baitinger et al., 1983).

Rat-202-positive neurons and axons are clearly evident in the spinal cord of E12 rats (Fig. 8 C). A very small number of Rat-202positive cell bodies and axons have been found at the most developed (rostral cervical) levels in E11 animals (Fig. 8, $A$ and $B$ ). Other studies using silver methods and electron microscopy have reported

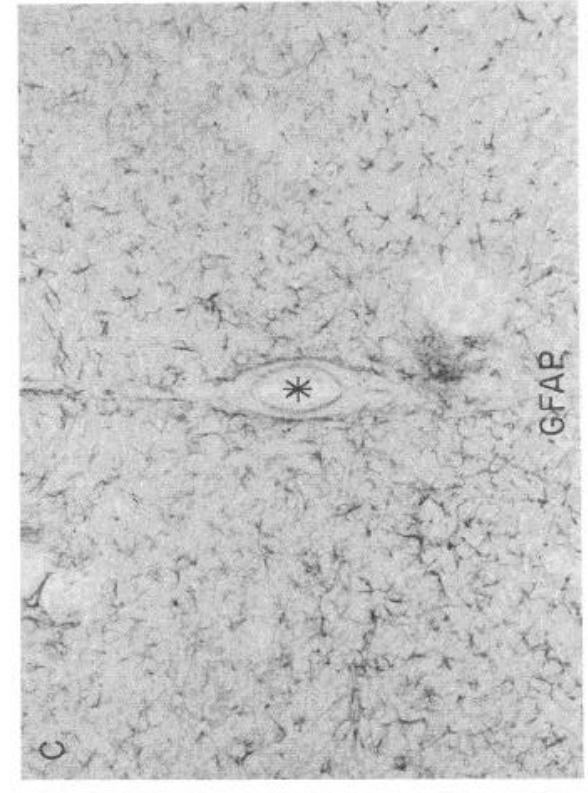

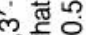

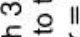

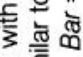
\& $\frac{\mathrm{E}}{\mathrm{c}}$

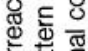
㐘 䑰

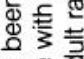
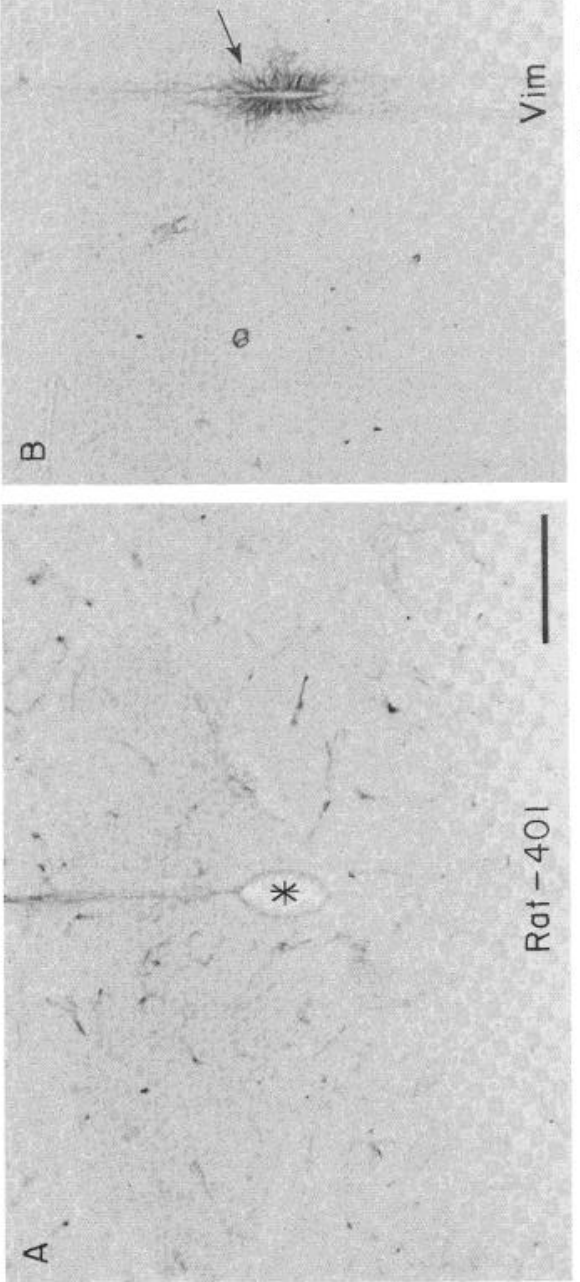

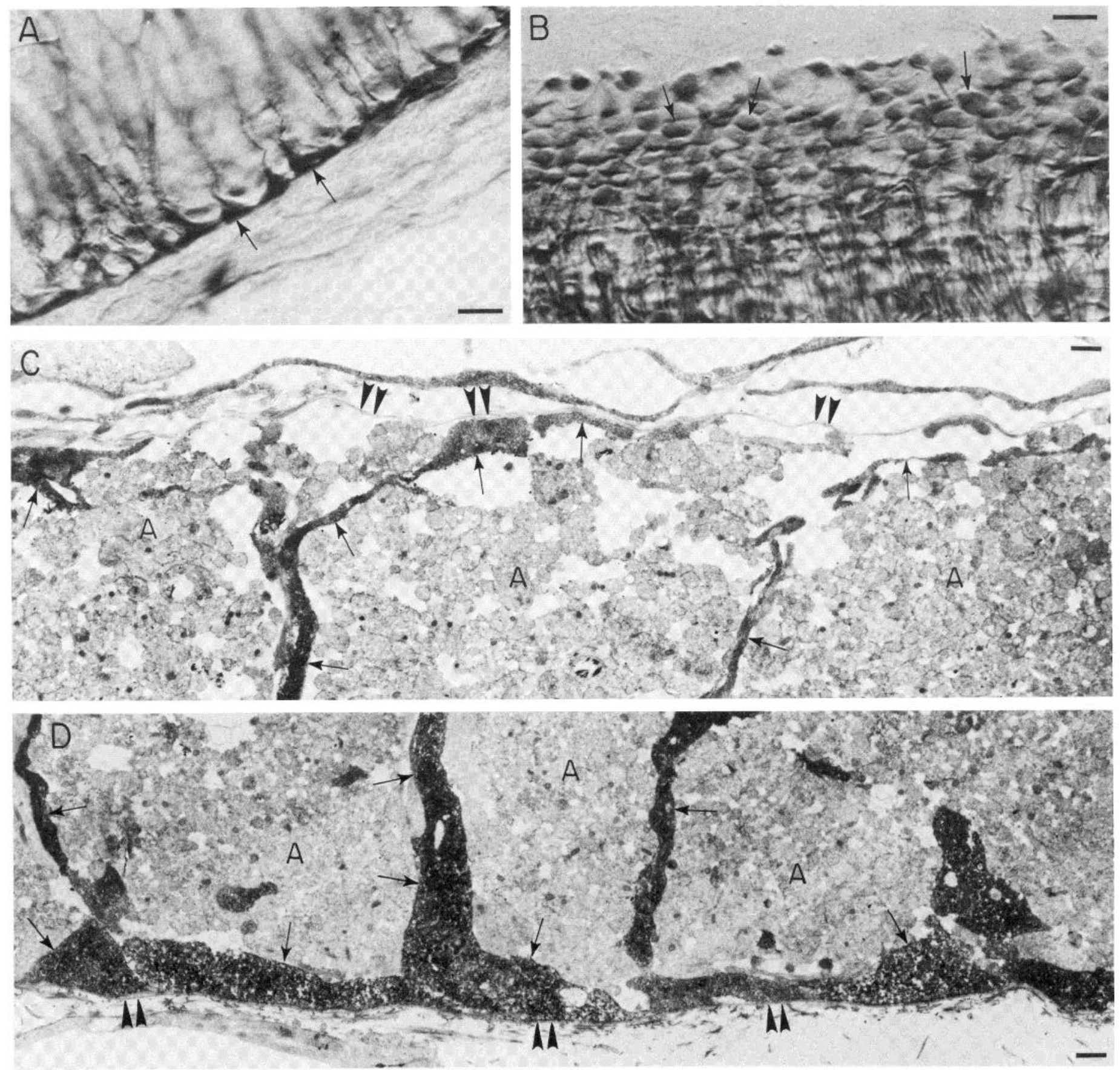

Figure 4. Rat-401 staining along the pial surface of $\mathrm{E} 15$ spinal cord. $A$, In transverse sections Rat-401-positive processes terminate in expansions, or endfeet (arrows) at the pial surface. $B$, In longitudinal section, the end-feet along the ventral margin of the spinal cord appear as flattened, circular profiles (arrows) that form an almost continuous sheet along the pial surface. Bars $(A$ and $B)=10 \mu \mathrm{m}$. $C$. At the electron microscopic level, transverse sections show that, along the dorsal surface of the spinal cord, Rat-401-positive processes (arrows) course among large groups of unstained axons (A) to end in small expansions against the basal lamina (arrowheads) of the pial surface. Rat-401-positive processes do not form a continuous boundary between axons and basal lamina. $D$, In contrast, along the ventral surface of the spinal cord, Rat-401-positive processes course among axons, expanding at the pial surface to form a continuous band interposed between the axons $(A)$ and the basal lamina (arrowheads). Bars $(C$ and $D)=1 \mu \mathrm{m}$.

the first appearance of axons in the rat neural tube at E12 (Windle and Baxter, 1936; Vaughn and Greishaber, 1973). This suggests that Rat-202 detects early axons with a sensitivity comparable to these other methods.

We have used Rat-202 to follow events in both peripheral and central axon growth. In the periphery axons in the ventral root precede those in the dorsal root. As axons leave the ventral root they form fascicles (Fig. 8C). When dorsal and ventral roots join to form the spinal nerve, axons can be seen to leave one fascicle to join another (Fig. 8D). At this stage and at later stages in axon development (E13 and later) Rat-202 appears to stain the entire growing axon as it can be seen in growth cones at the light and electron microscopic levels (Figs. 9 and 10). By E13 nerve bundles are clearly stained (Fig. 9A), and Rat-202 staining shows that axons group tightly together throughout most of their length. At the tip of a developing nerve many axons end in a terminal enlargement with 

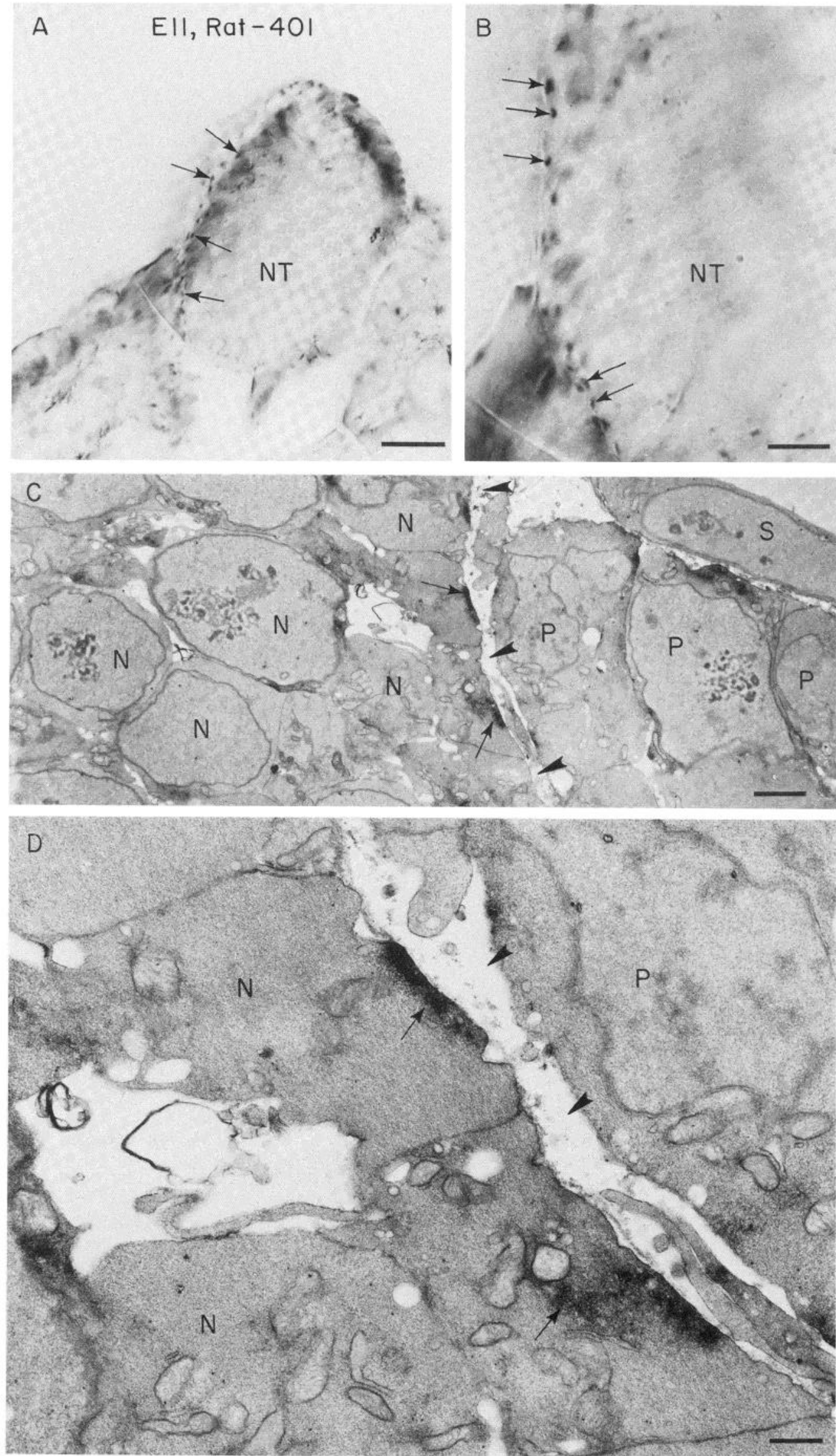

Figure 5. Antibody Rat-401 begins to stain CNS at E11. A, Rat-401 staining is first seen as small, punctate areas (arrows) along the pial surface of E11 neural tube (NT). Bar $=100$ $\mu \mathrm{m}$. $B$, Higher magnification light $\mathrm{mi}$ crograph of the pial surface shows the peripheral location of Rat-401-positive profiles (arrows). Bar $=50 \mu \mathrm{m}$. C, An electronmicrograph of the dorsolateral surface of an immunostained section from an E11 animal showing cells in the neural tube $(N)$, peripheral cells $(P)$, and skin cells $(S)$. A space containing extracellular material separates the neural tube from the peripheral cells (arrowheads). Antibody-stained processes are seen along the lateral border of the neural tube (arrows). Bar $=2 \mu \mathrm{m}$. D. Higher magnification electron micrograph of the lateral border of the neural tube shows that the antigens recognized by Rat-401 (arrows) do not fill antibody-positive cells but are concentrated in small dense patches on the pial surface, corresponding to the picture at the light microscopic level. Bar $=0.5 \mu \mathrm{m}$. 

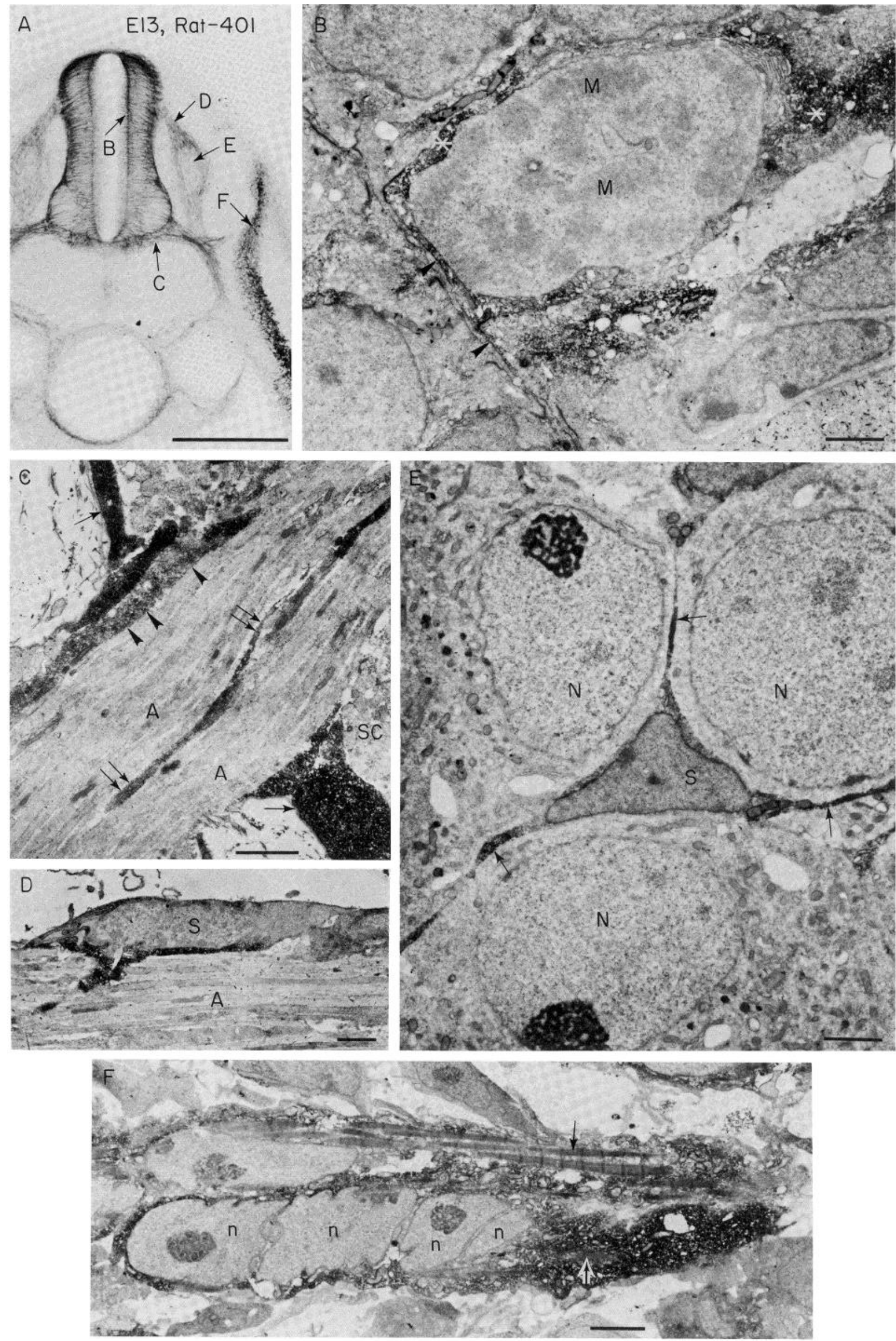
Cerebellum: P2

A

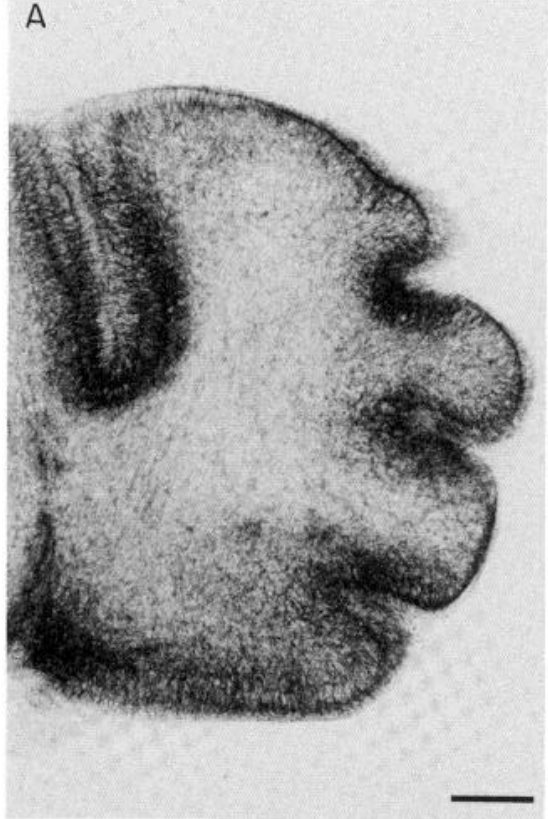

Spinal Cord:

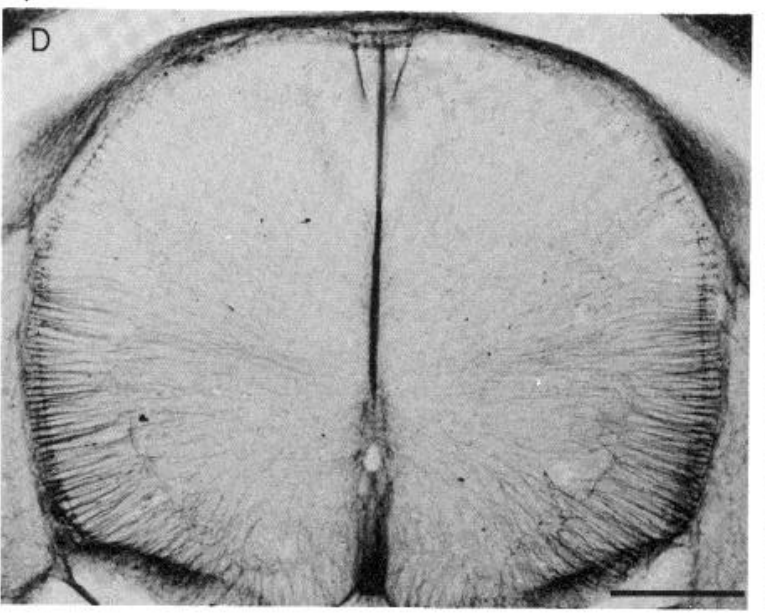

$\mathrm{Pl} 2$

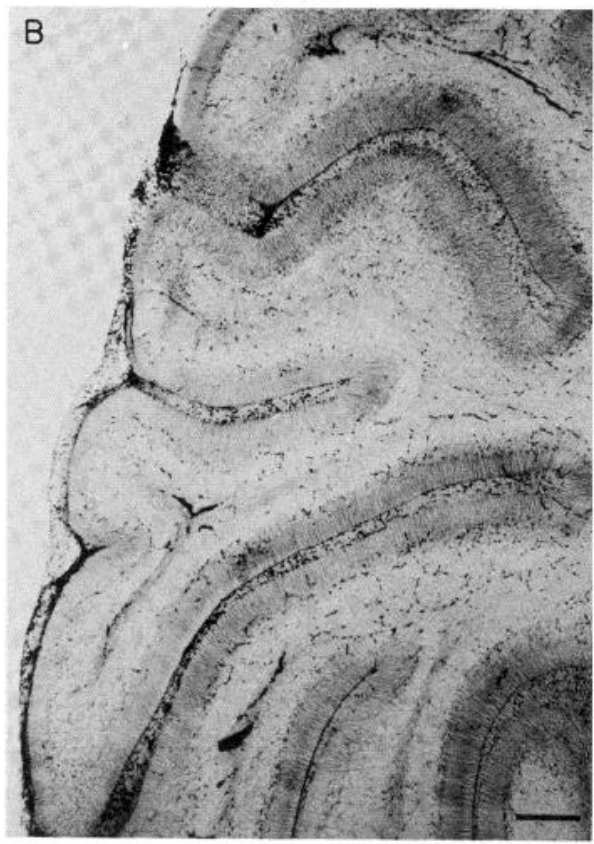

P2

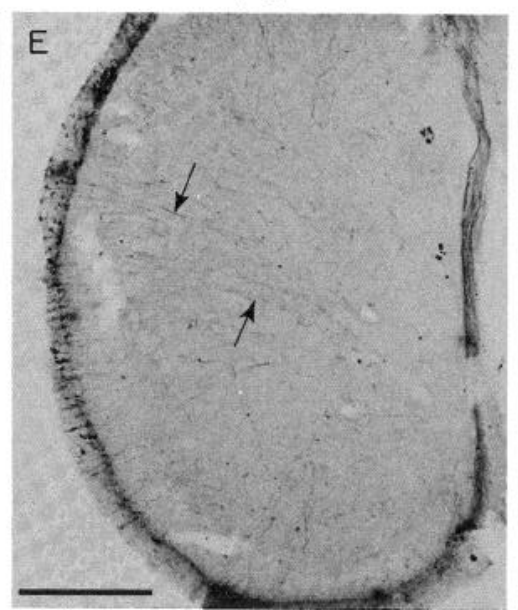

P28

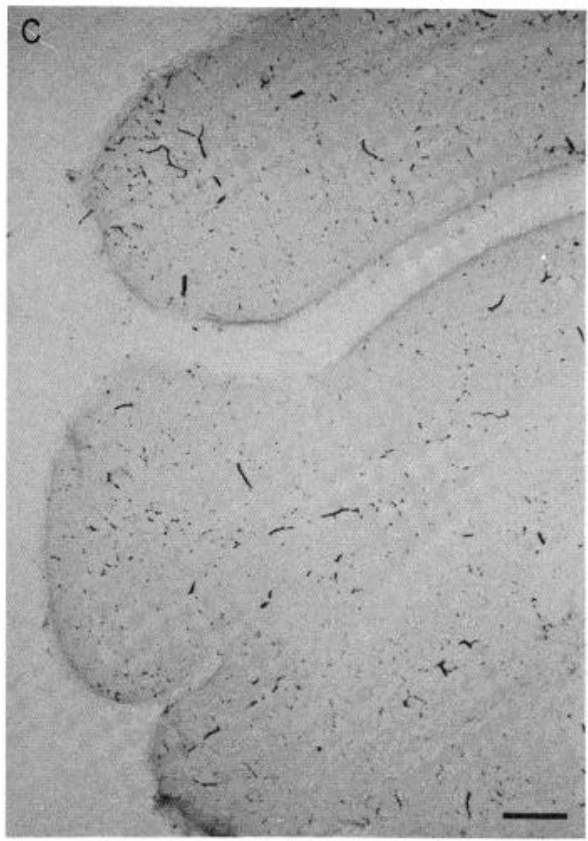

P6

F

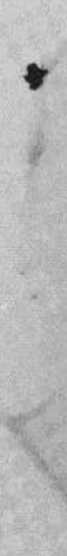

Figure 7. Antigens recognized by Rat-401 are lost during development in cerebellum ( $A$ to $C)$ and spinal cord $(D$ to $F)$. $A, P 2$ cerebellum contains numerous Rat-401-positive profiles. B, By P12 the intensity of Rat- 401 staining begins to decrease. $C$, At P28 the cerebellum contains no Rat-401-positive profiles. The loss of Rat-401 staining is achieved by P21. In the developing cerebellum the majority of neuronal proliferation and migration is complete by P21 (Altman, 1972). D, In the spinal cord, Rat-401 staining begins to decrease at $\mathrm{E} 19$ (compare with $\mathrm{E} 15$ in Fig. $1 B$ ). $E, A t \mathrm{P} 2$ very few antibody-positive profiles remain in the spinal cord (arrows). F, By P6 the spinal cord contains no positive profiles. In the spinal cord, neuronal proliferation and migration are complete by E19 (Nornes and Das, 1974). Bars $=1 \mathrm{~mm}$.

fine filopodia arising from the enlargement (Fig. 9B). Often, under Nomarski optics, the enlargement appears vacuolated and these profiles match those previously described as growth cones.

In the CNS, Rat-202 also stains the entire axon, including its growth cone (Fig. 10). In the dorsal horn at E15 two types of axonal endings have been observed. One arises from axons that course ventrally and then turn dorsally to end in a vacuolated enlargement with many fine processes arising from it (Fig. 10C). The other type arises from axons that enter the dorsal horn from the medial border and end in a slender enlargement with a single filopodium or few filopodia emerging from it (Fig. 10D). At the electron microscopic level these antibody-positive enlargements contain large vesicles

Figure 6. Rat-401 staining of E13 to E17 animals. A, At E13 there are many more Rat-401-stained processes than at E11 (cf. Fig. 5). At the light microscopic level, antibody-stained processes are found in the spinal cord $(B)$, in axon roots $(C$ and $D)$, in the dorsal root ganglia $(E)$, and in developing muscle $(F)$. Bar $=1 \mathrm{~mm}$. B. Electron micrograph of the ventricular zone showing a Rat-401-positive cell (white asterisk) whose nucleus contains mitotic figures $(M)$. Arrowheads indicate the ventricular surface. $C$. The ventral root as it emerges from the spinal cord (SC). Rat-401-positive profiles line the pial surface (arrows) and extend along the ventral root as it courses from CNS to PNS (arrowheads). Positive profiles are also seen within the body of the root (double arrows), intermingling with antibody-negative axons $(A) . D$, In peripheral nerve, cells that resemble the Schwann cells in adult nerve are Rat-401 positive $(S)$ in embryos. They lie along nerve roots in direct contact with axons $(A)$. $E$, In the dorsal root ganglia Rat-401-positive cells $(S)$ lie among unstained neurons $(N)$. Antibody-positive processes (arrows) extend between the neurons. $F$, Rat-401-positive cells in the developing muscle masses are often multinucleate $(n)$ and contain myofibrils (arrows). In $B$ to $F$, bar $=2 \mu \mathrm{m}$. 

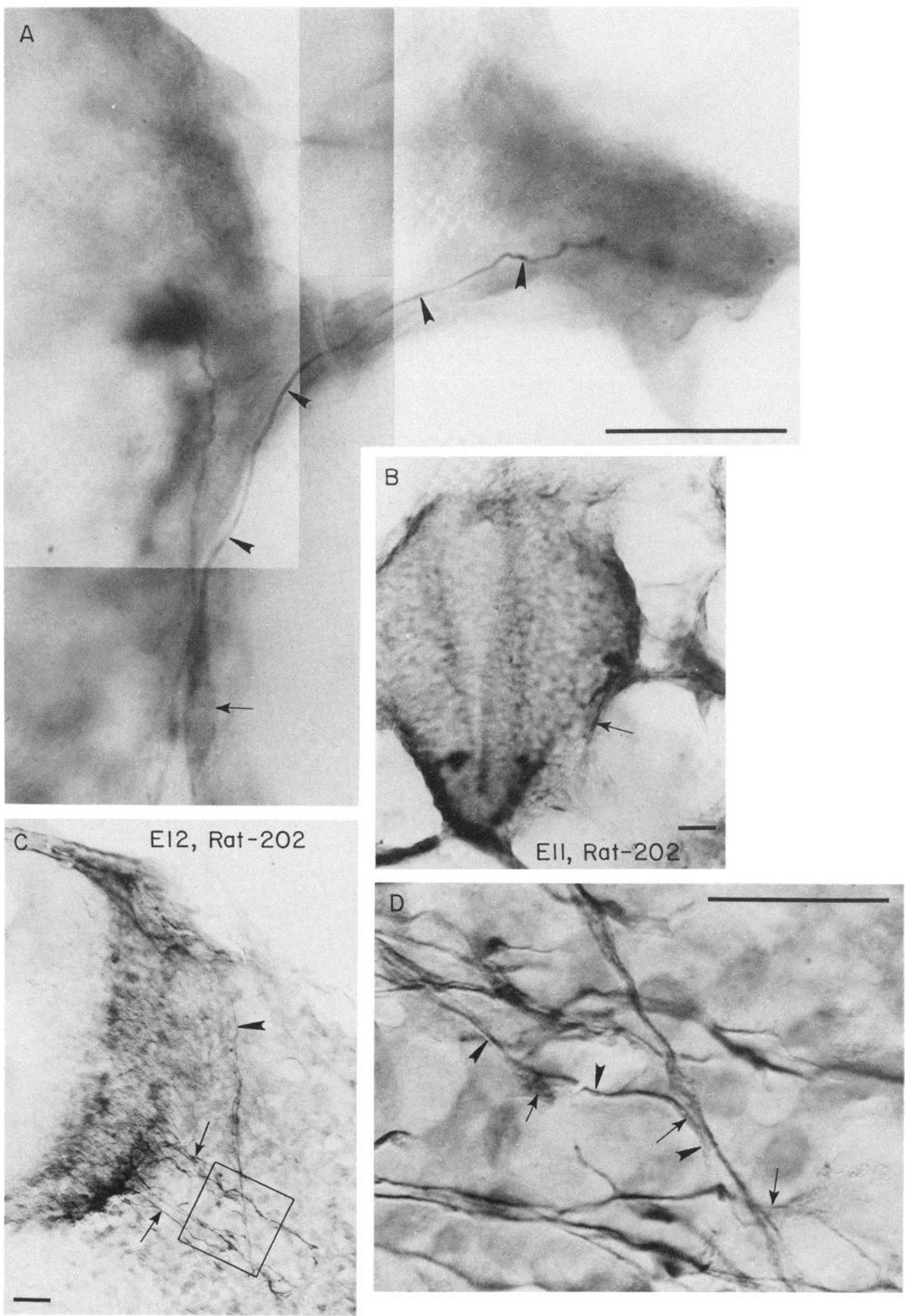

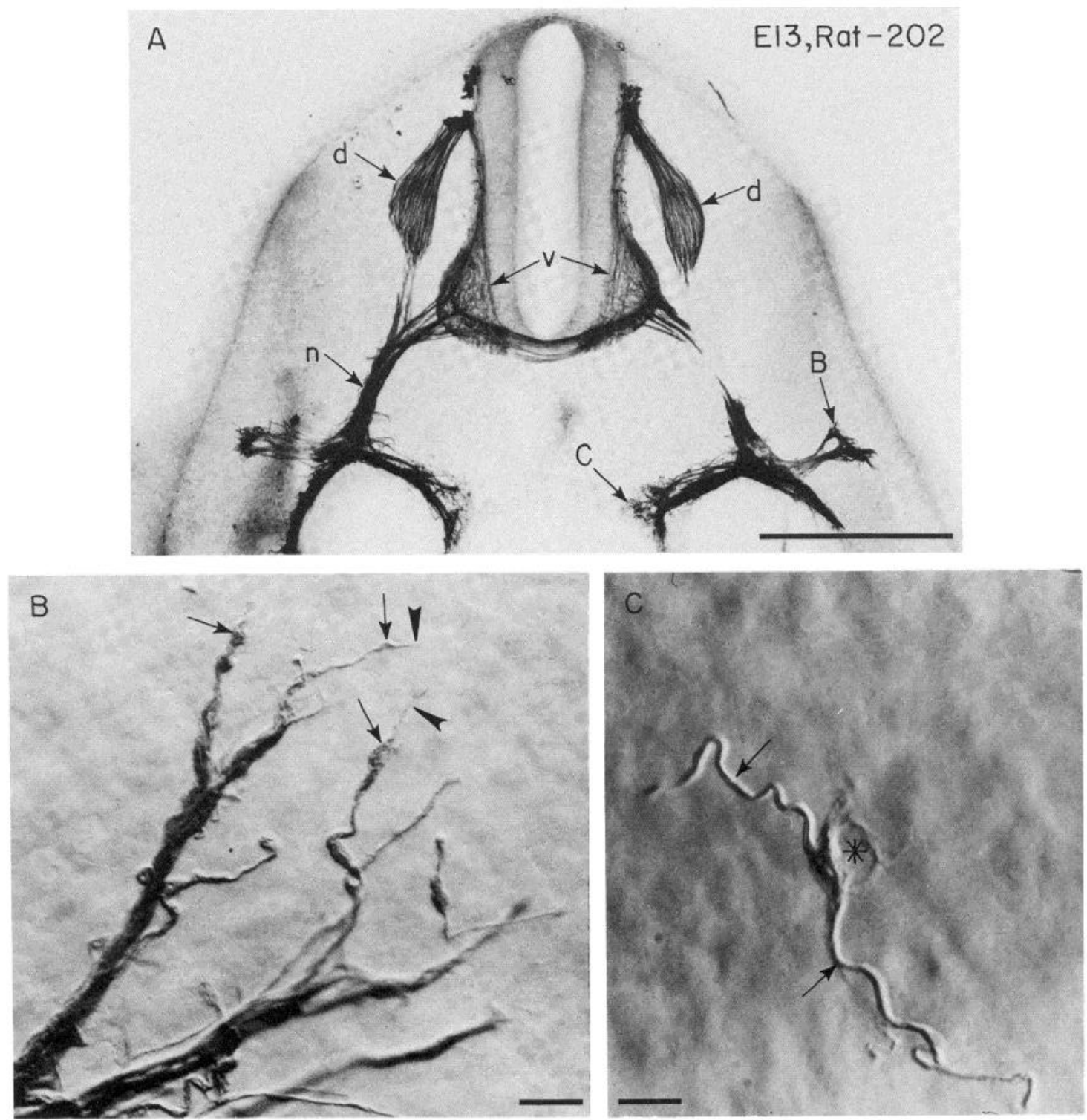

Figure 9. Rat-202 staining at E13. A, By E13 a large number of axons are stained by Rat-202, clearly showing the developing dorsal root ganglia (d), ventral horns $(v)$, and peripheral nerves $(n)$. The dorsal horn has not developed at this stage (cf. Fig. 10A). In the periphery, axons extend toward muscle masses $(B)$ and around the gut $(C)$. Bar $=1 \mathrm{~mm}$. B. High magnification of a group of axons growing through the periphery at the site of a developing muscle. The tips of many axons end in enlargements (arrows) with fine filopodia extending from them (arrowheads), matching descriptions of growth cones. The enlargements under Nomarski optics appear vacuolated. Bar $=20 \mu \mathrm{m}$. C, Antibody-positive axons (arrows) innervating new areas, especially around the gut, are seen in association with another cell (asterisk). Bar $=20 \mu \mathrm{m}$.

and have irregular profiles, similar to the description of growth cones (Fig. 10C). The filopodia arising from these growth cones contact other processes that are unstained by Rat- 202 .

\section{Antibody Rat-401 recognizes peripheral cells}

In addition to the radial glia in the CNS, Rat-401 also recognizes cells in peripheral structures including developing muscle, dorsal root ganglia, and peripheral nerve roots.
In the developing muscle masses, electron microscopic immunocytochemistry shows that Rat-401 recognizes multinucleate cells that often contain myofibrils (Fig. $6 F$ ). Mononucleate cells also are stained, but it is not possible without electron microscopic serial reconstructions to determine whether these are truly mononucleate. However, at E11, when the myoblasts begin to leave the somite, the ventral layer of cells (the myotome) from which the myoblasts arise is recognized by Rat-401. The dorsal layer (the dermatome) that gives rise to the dermis is antibody negative. This evidence

Figure 8. Rat-202 stains early axons. $A$ and B, At E11 a small number of Rat-202-positive neuron cell bodies and axons can be seen at rostral cervical levels of the developing neural tube. The low magnification micrograph $(B)$ illustrates the position of a stained cell body in the ventral portion of the neural tube (arrow). At higher magnification $(A)$ a stained cell body (arrow) and the path of its axon (arrowheads) dorsally and out of a root are illustrated. C, At E12 the number of Rat-202-positive axons has increased. Many axons course out of the ventral root (arrows), and a few have begun to form the dorsal root (arrowhead). D, Higher magnification of the juncture of the dorsal and ventral roots, from the boxed region in $C$, shows a number of growth cones (arrows) and also shows axons leaving one fascicle to join another (arrowheads). Bars $=100 \mu \mathrm{m}$. 


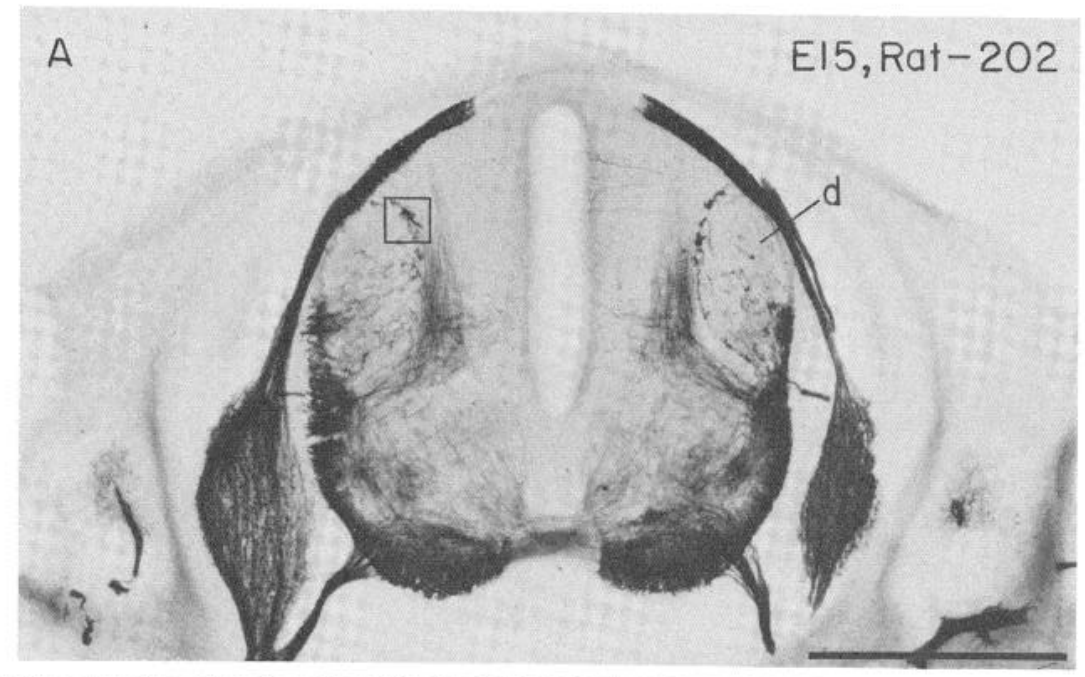

Figure 10. Developing axons in the CNS at E15. A, By E15 the dorsal horn (d) has begun to form (compare with E13 in Fig. 9A) Rat-202-stained axons course around and into the dorsal horn. Bar $=1 \mathrm{~mm}$. B. Enlargement of the boxed area in $A$ shows numerous processes. Boxes $C$ and $D$ are enlarged at the right, showing two types of growth profiles. Bar $=10 \mu \mathrm{m}$. C, A growing axon courses ventrally and then swings dorsally to end in a vacuolated enlargement (arrow) with an array of fine processes (arrowheads) arising from it. Bar $=2 \mu \mathrm{m}$. D, An axon courses from medial to lateral, terminating in a slender enlargement (arrow) with a single fine process (arrowhead) arising from it. Bar $=2 \mu \mathrm{m}$. $E$, Electron micrograph of a profile similar to that shown in D. A Rat-202-positive axon, coursing from right to left, ends in a vacuolated enlargement (arrows) with a fine, antibody-positive process extending from it (arrowheads) that contacts an unstained profile $(u) . B a r=1 \mu \mathrm{m}$.
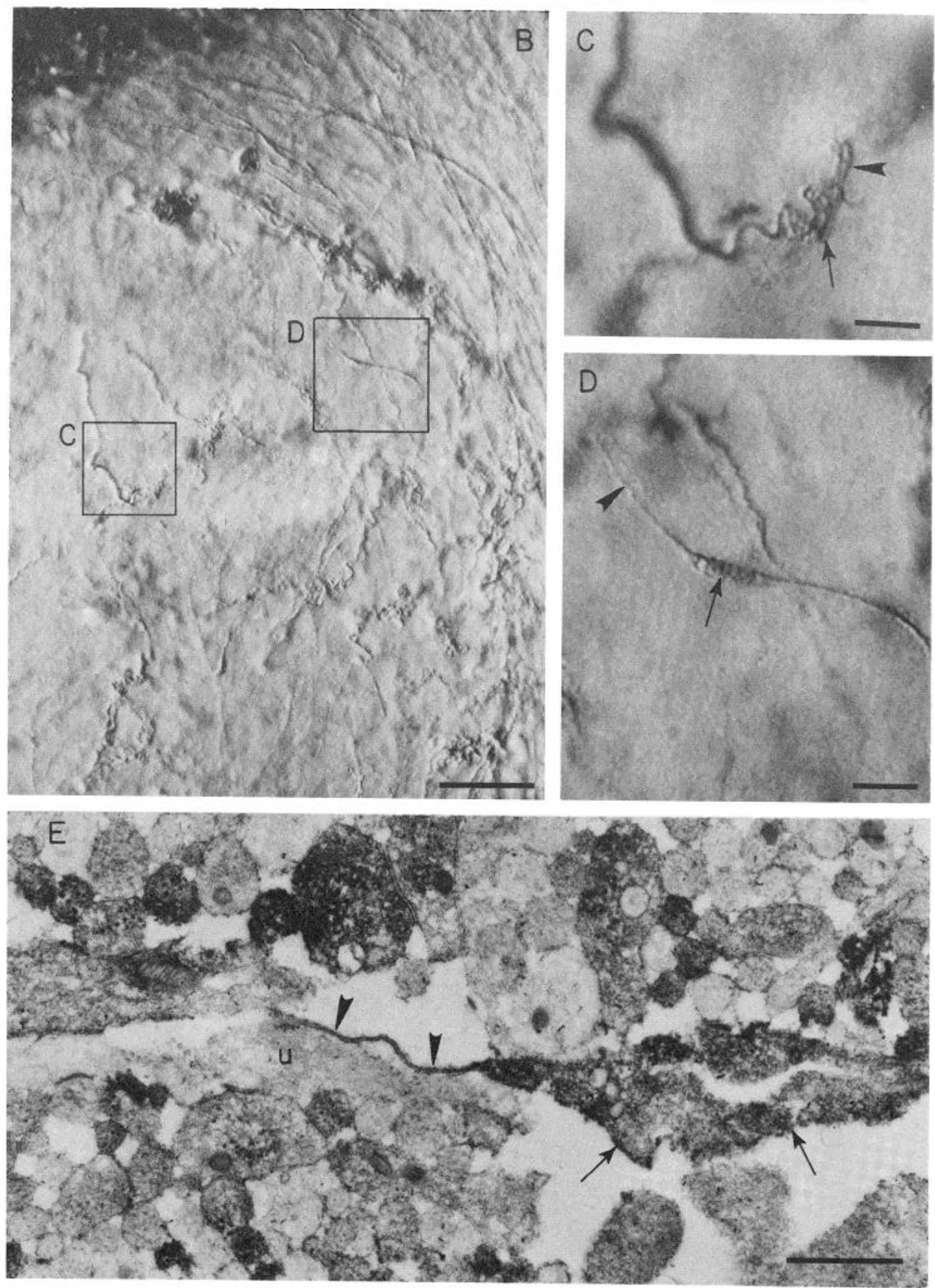
Rat-202

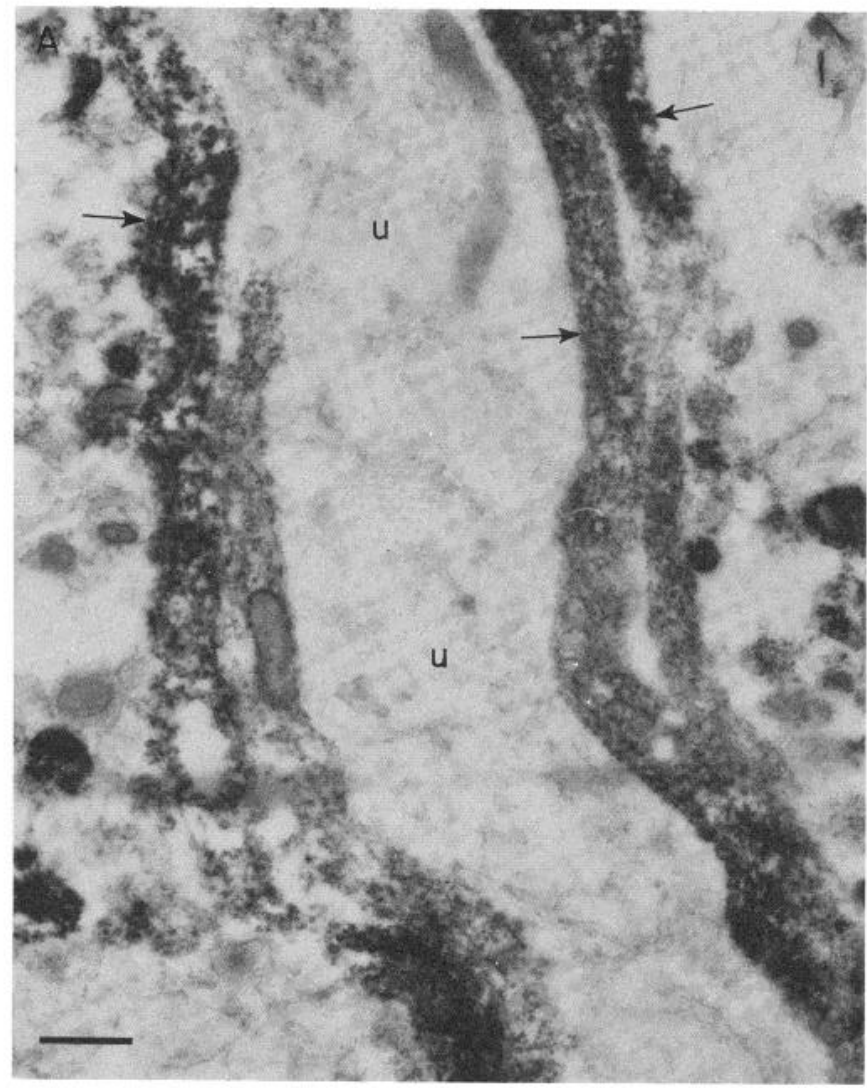

Rat -401

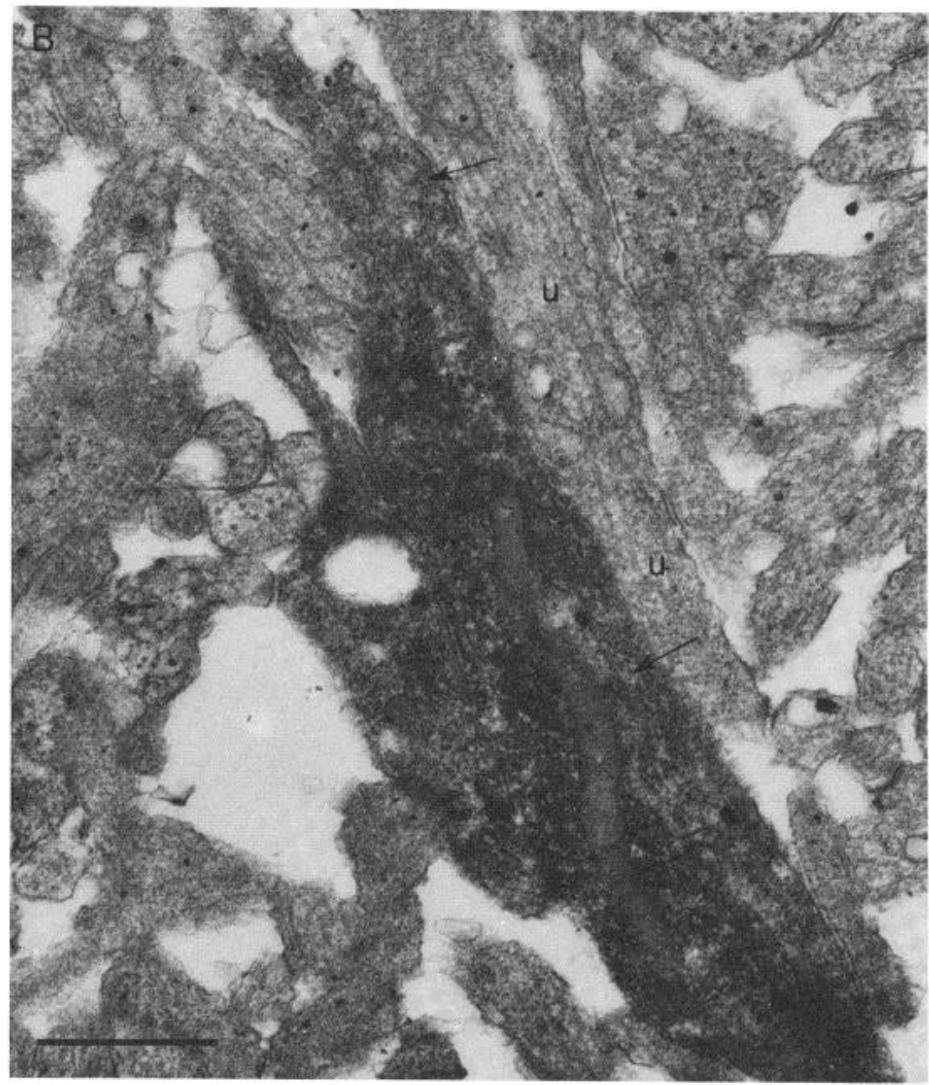

Figure 11. Electron micrographs of Rat-202- and Rat-401-stained processes. A, Rat-202 stains processes (arrows) in the spinal cord that are closely

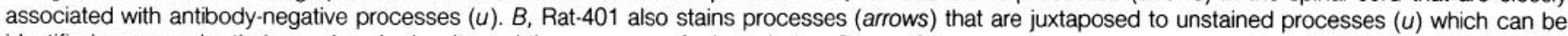
identified as axons by their axoplasmic density and the presence of microtubules. Bars $=0.5 \mu \mathrm{m}$.

suggests that both myoblasts and myotubes contain Rat-401 antigens. Mature muscle cells are not stained by Rat- 401 .

Neural crest cells are Rat-401 positive as they leave the neural tube and migrate through the periphery. Several, but not all, neural crest-derived populations of cells express Rat-401 antigens. In the dorsal root ganglia at E15, Rat-401 stains non-neuronal cells. Rat401-positive cells in the dorsal root ganglia, resembling the adult satellite cells, lie among unstained neurons. They extend fine processes to surround neurons and blood vessels (Fig. 6E). In the adult, the satellite cells in the dorsal root ganglia are also Rat-401 positive.

In peripheral nerve, as in the dorsal root ganglia, Rat-401 does not stain axons but stains non-neuronal cells associated with axons (Fig. 6, $C$ and D). These non-neuronal cells resemble the Schwann cells of adult nerve. The Schwann-like cell bodies are Rat-401 positive, and Rat-401-positive processes lie among axons in peripheral nerves. In mature nerve, Schwann cells are stained by Rat-401.

As the ventral root courses from CNS to PNS, Rat-401-positive processes intermingle with the exiting axons. Some processes lie along the perimeter of the nerve root and others lie within the emerging root, juxtaposed to neighboring unstained axons (Figs. $6 C$ and $11 B$ ). The converse of this picture is seen in roots stained with Rat-202 where antibody-positive axons are seen juxtaposed to unstained profiles (Fig. 11A). These data suggest that Rat-202positive axons, like neuron cell bodies, lie directly adjacent to Rat401-positive cell processes.

\section{Rat-401 processes precede axons in the ventral root}

At E11, our data utilizing Rat-202 and other electron microscopic studies show that axons have not yet grown out of the ventral root at most levels of the developing neural tube. Rat-401-positive processes are seen in the position of the ventral root at E11 before axon outgrowth (Fig. 12). Alternate sections stained with Rat-202 and Rat-401 confirm that Rat-401-positive processes are seen in the position of the ventral root before Rat-202-positive axons. At E11, Rat-401 processes at the surface of the neural tube span the region between the CNS and the periphery (Fig. 12, B and D). In 2- $\mu \mathrm{m}$ thick plastic sections some Rat-401 processes appear to course from inside the CNS out to the periphery (Fig. 12D).

\section{Antigenically distinct periods in axon development}

Morphological studies on the formation of connections suggest that there are distinct phases in axon development (Rakic, 1976; Dennis et al., 1981; Jones et al., 1982). We have previously reported two monoclonal antibodies which recognize antigens present in the axons of adult vertebrate neurons, Cat-101 and Cat-201 (McKay and Hockfield, 1982). We report here that Rat-202, Cat-101, and Cat-201 are each expressed at characteristic times in axon development

Cat-101 stains axons but not cell bodies in the spinal cord and in all other areas of the adult CNS we have examined. Cat-201 also intensely stains axons but, in addition, stains some neuron cell bodies. The ventral horn contains several groups of Cat-201-positive cell bodies; however, most neuron cell bodies in the spinal cord (and throughout the CNS) are not recognized by Cat-201. Electron microscopic immunocytochemistry has confirmed that Cat-101 and Cat-201 recognize axons. Both antibodies bind to internal antigens in axons and not to the myelin sheath or other supporting cells. Not all axons contain antigens recognized by these antibodies; for example, in the cerebellum the granule cell axons (the parallel fibers) are not recognized by either antibody (see McKay and Hockfield, 1982). In most areas Cat-101 and Cat-201 appear to recognize the same population of axons.

Cat-101 and Cat-201 recognize antigens present on proteins 

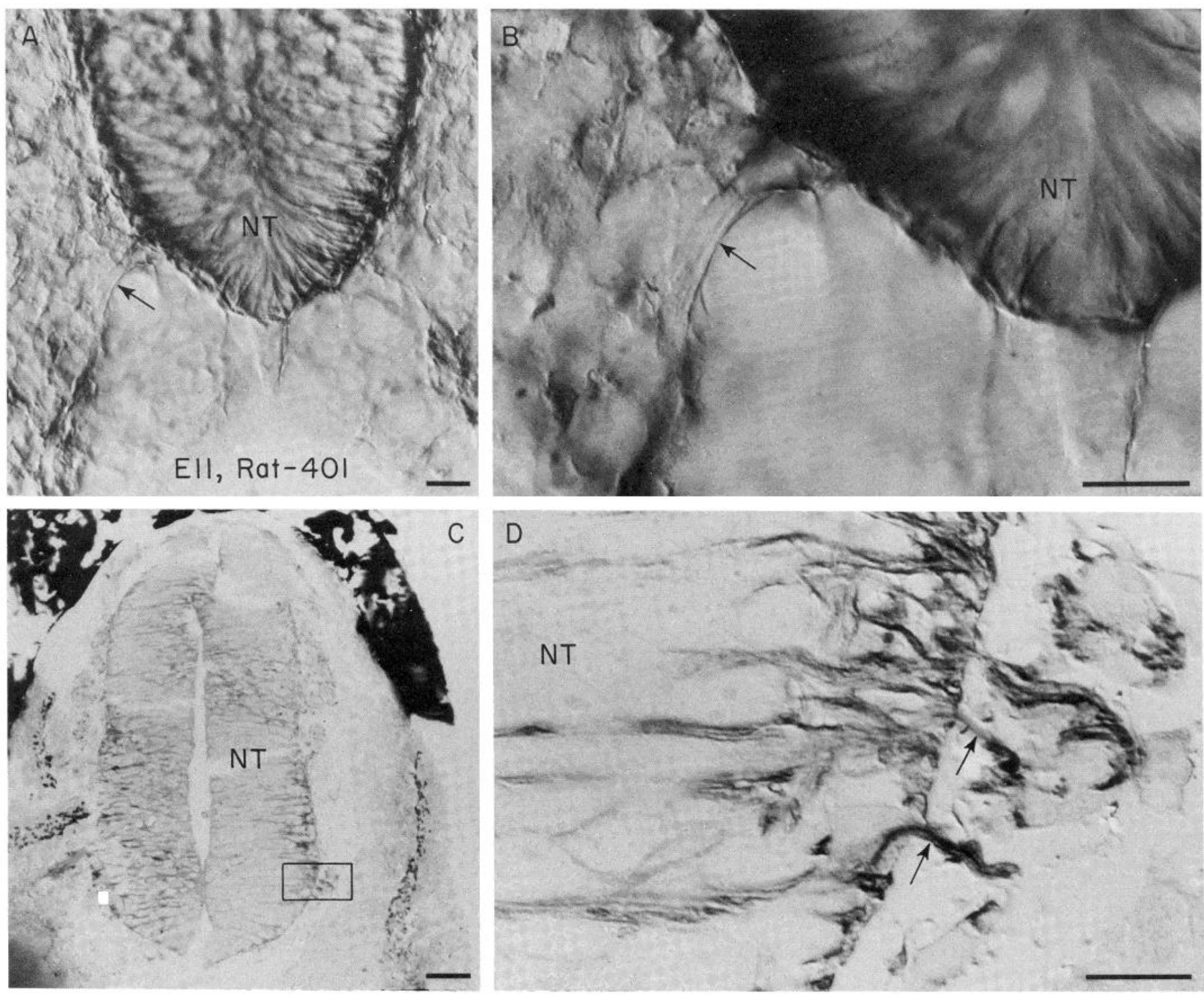

Figure 12. Rat-401-positive processes precede axons in the ventral root at E11. A, A 50- $\mu$ m-thick section of E11 neural tube (NT) shows Rat-401-positive processes in the position of the future ventral root (arrow). Bar $=100 \mu \mathrm{m}$. B. Higher magnification of $A$ shows a process (arrow) extending from the neural tube (NT) into the periphery. Bar $=50 \mu \mathrm{m}$. C, A 2- $\mu \mathrm{m}$-thick plastic section of Rat-401-stained E11 spinal cord. The area in the box is shown enlarged in $D$. $B a r=300 \mu \mathrm{m}$. D. High magnification of the area of the future ventral root shows Rat-401-positive profiles extending from within the CNS to the periphery (arrows). Bar $=50 \mu \mathrm{m}$.

extracted from the adult cat brain. On immunoblots of SDS-polyacrylamide gels both of these antibodies bind to 210-kd proteins which co-migrate with the large subunit of the neurofilament triplet (Fig. 2). To verify that the antibodies were binding to similar antigens in unfixed tissue used in the biochemical analysis and in fixed tissue used in the histological analysis, fresh frozen tissue was sectioned on a cryostat and processed for immunochemistry. The staining patterns in these preparations were identical to those in fixed tissue sections.

During development, the Cat-101 and Cat-201 antigens appear at different times (Fig. 13). Cat-101 appears earlier than Cat-201. Neither antibody binds to sections of E15 rat spinal cord or to bands on immunoblots of proteins extracted from E15 spinal cord. Cat-101 stains axons in the E17 rat spinal cord, whereas Cat-201 does not (Fig. 13, $B$ and $C$ ). The number of axons recognized by Cat-101 increases over the late embryonic and early postnatal periods. In contrast, Cat-201 does not extensively stain the spinal cord until the third postnatal week. This developmental progression of axonal staining probably does not reflect the ingrowth of new axons but, rather, a maturational feature of axons already present since antibody Rat-202, which recognizes axons from the earliest stages of neurite outgrowth, shows that axons are present but unstained by Cat-101 or Cat-201 as early as E12, and throughout late embryonic and early postnatal stages.

We have examined the time course of Cat-101, Cat-201, and Rat202 staining in early postnatal cats as well as rats. In the cat at birth all three antibodies stain axons and Rat-202 and Cat-201 stain cell bodies (Fig. 13, $D$ and $F$ ). In the cat, as in the rat, developmental changes are seen over the first 3 postnatal weeks. Not all of the axons that are Cat-101 and Cat-201 positive in the adult are antibody positive at day 1 . For example, axons in the dorsolateral white matter (the area of the corticospinal tract and dorsolateral funiculus) are not stained at birth (Fig. 13, E and F). In contrast, Rat-202 does stain axons in the corticospinal tract and the dorsolateral funiculus at P1 (Fig. 13D). In the adult all three antibodies stain axons in the dorsolateral funiculus and in the corticospinal tract (Fig. 13, G, H and $I$ ). These results show that the timing of the expression of these axonal antigens marks particular phases in axon maturation in vivo. 
Rat-202

EI7

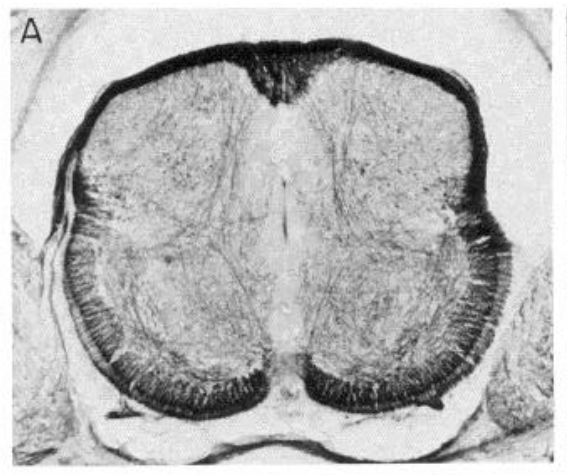

PI
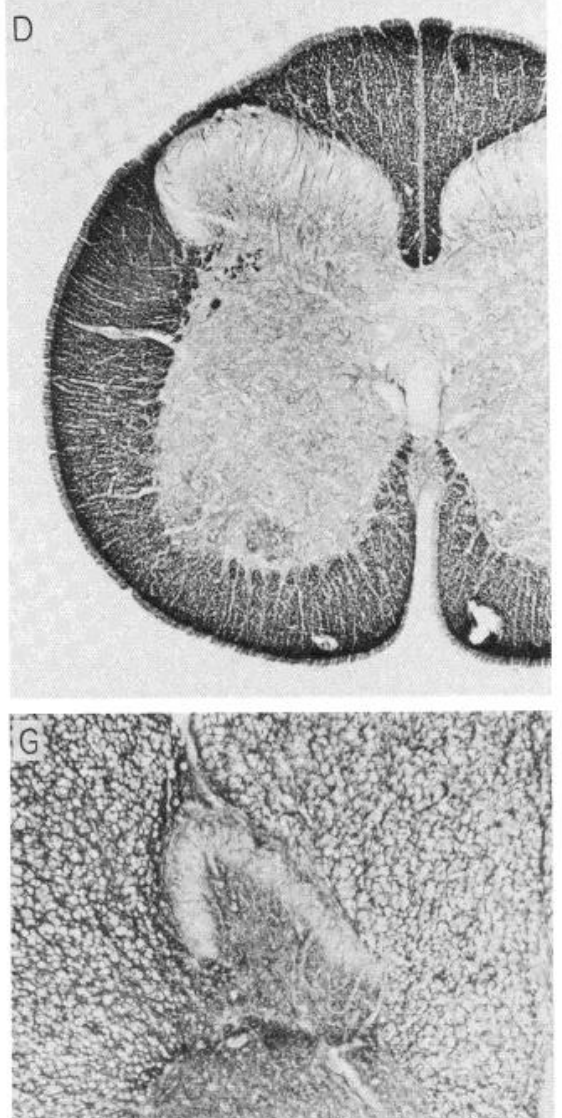

Adult

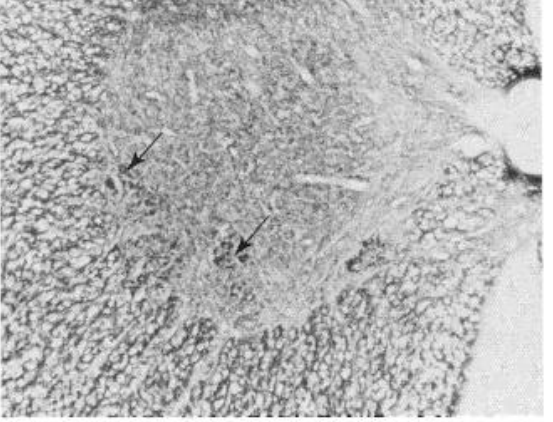

Cat-IOI

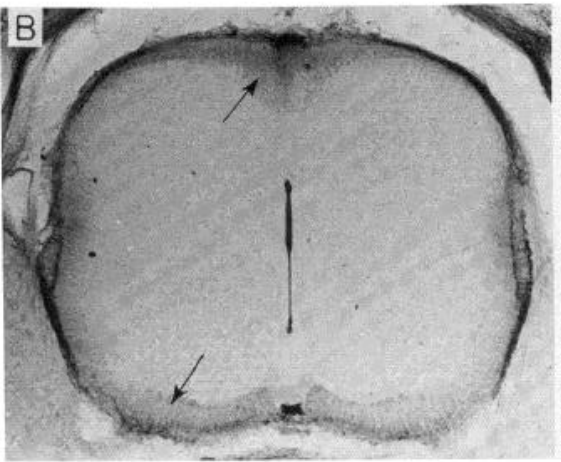

E

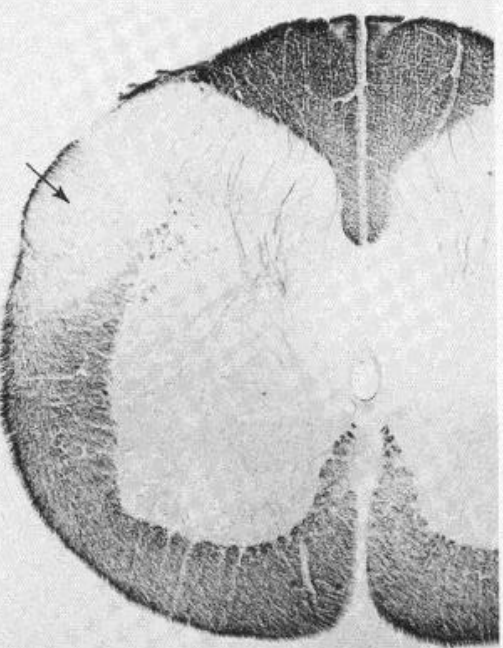

H
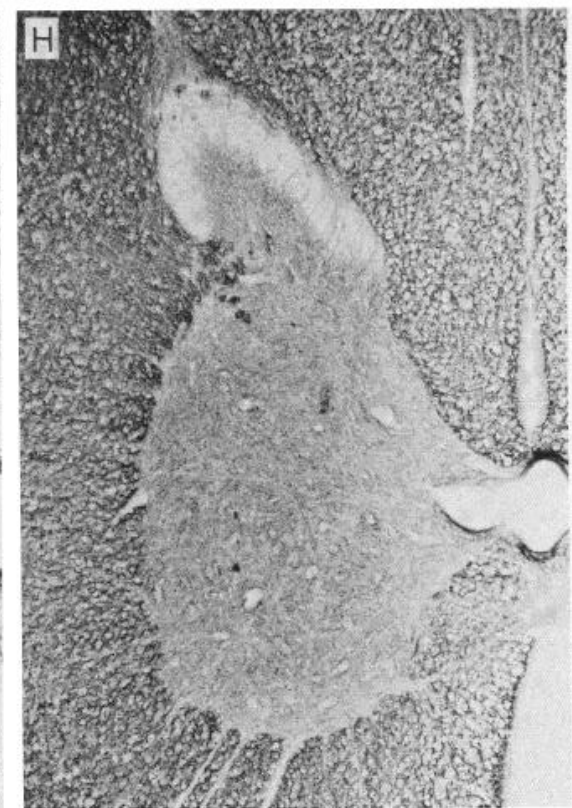

Cat-2OI

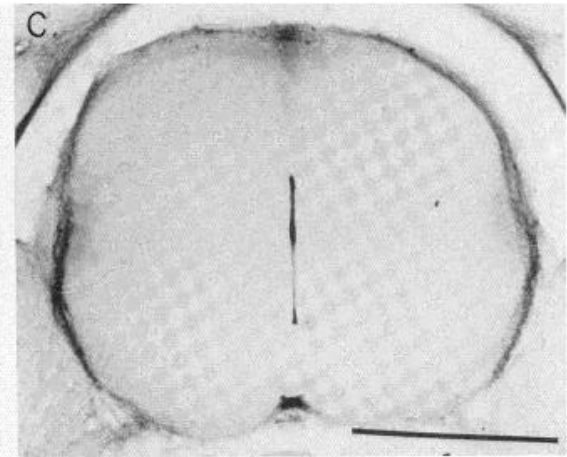

F
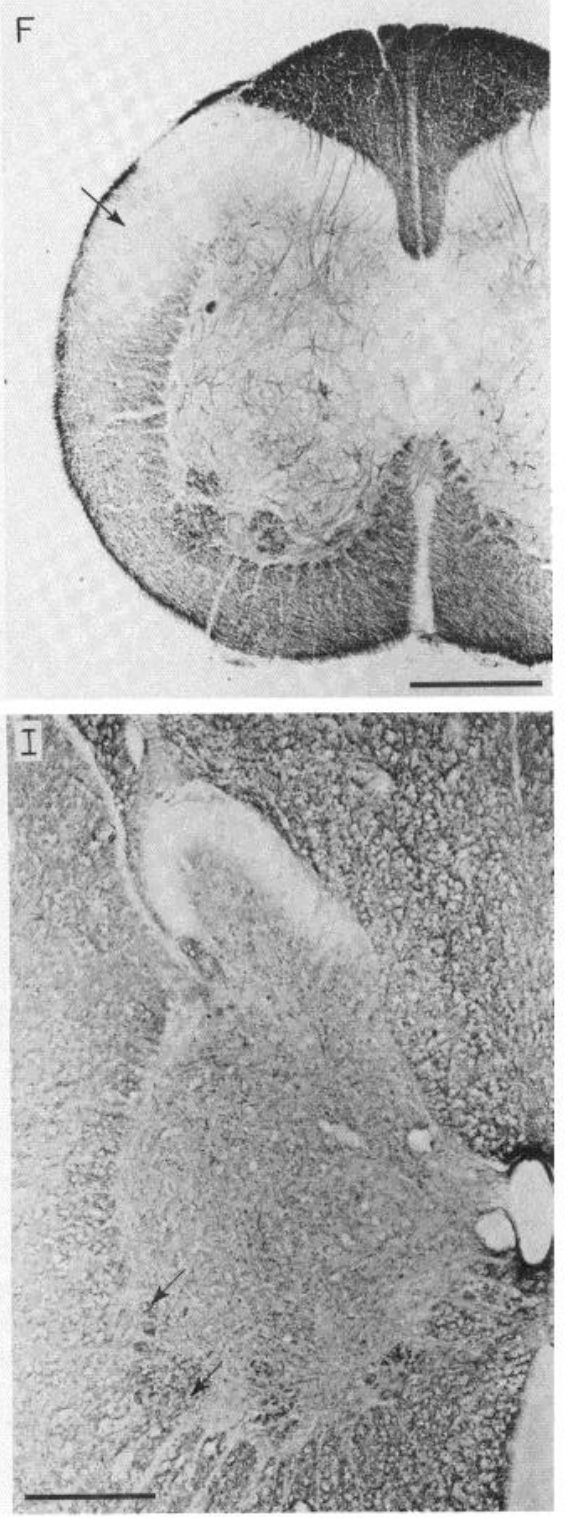

Figure 13. The antigens recognized by antibodies Rat-202, Cat-101, and Cat-201 each have a different time course of expression. At E15 in the rat, only Rat-202 stains axons (see Fig. 1). A to C, At E17 Rat-202 stains a large number of axons, whereas Cat-101 stains only a small population (arrows in B) and Cat-201 does not stain any axons. In the rat, Cat-201 first stains axons during the second postnatal week. $D$ to $F$, At P1 in the cat, all three antibodies recognize axons. The entire white matter is filled with Rat-202-positive axons, but a group of axons in the dorsolateral funiculus (arrows in $E$ and $F$ ) is unstained by either Cat-101 or Cat-201. G to $I$, In the adult cat all three antibodies show a similar pattern of axonal staining. In addition to axons, Rat-202 and Cat-201 recognize some neuron cell bodies (arrows in $G$ and $I$ ), whereas Cat-101 recognizes only axons $(H$ ). Bars $=0.5 \mathrm{~mm}$. 
The developing vascular system is recognized by lectins

In addition to generating monoclonal antibodies, we have also screened several lectins for their ability to recognize subsets of cells in the neural tube. Lectins from BAND bind to developing blood vessels in the embryonic neural tube (Fig. 14).

The CNS vasculature begins to develop at E12 when cells invade from the periphery. The ventral horn is vascularized before the dorsal horn, following the ventral-to-dorsal gradient described for other features of development (Nornes and Das, 1974). The vasculature grows both by addition of invading cells and by the established endothelial cells sending out fine, filopodia-like processes from nodes, or peaks, along the vessel surface (Fig. 14B). These processes contact one another to set up new blood vessels. In this way the very simple grid of initial vessels is elaborated into the more complex pattern seen at later developmental stages.

Clectron microscopy shows that BAND recognizes both the luminal and abluminal surfaces of developing endothelial cells (Fig. $14, C$ and $D$ ). The fine filopodia-like extensions from these endothelial cells are also BAND positive and form small, tight groups of three or four processes with no apparent lumen. These proceses increase in size and small-lumened vessels appear to form when these processes make stable contacts with one another at their lateral surfaces.

In the adult spinal cord, BAND recognizes a population of profiles distinct from those it recognizes in the embryo. In most cases, the adult vasculature is BAND negative, but the most dorsal layers of the spinal cord dorsal horn (layers I to III) contain a dense network of BAND-positive profiles. These results will be presented in more detail in a subsequent publication.

\section{Discussion}

During the course of mammalian neural development, a plate of anatomically homogeneous cells goes through a process of cell division and morphogenetic changes which gives rise to an adult nervous system composed of many thousands of cells with a variety of structures and physiology and with a complex but precise series of connections among them. In our previous work we have examined the molecular diversity among neurons in adult vertebrates (McKay and Hockfield, 1982; Hockfield et al., 1983) and invertebrates (Mckay et al., 1983) and shown that the number of molecularly distinct characteristics that vary among neurons is likely to be large, perhaps large enough to account for many of the anatomical and physiological differences observed among neurons. Two questions arose from these studies. First, when during development does this molecular diversity arise; and second, is there a time during neurogenesis when molecular diversity is small enough to allow us to obtain a more complete classification of the cells in the CNS? In our first efforts to study the developing mammalian nervous system we determined the time at which antigens recognized by monoclonal antibodies generated against the adult CNS arise. The antigens recognized by all of the antibodies we have tested are first expressed late in development, at a time after a neuron has achieved its adult position and many of its mature morphological characteristics (Hockfield et al., 1983). In this paper we have reported a series of markers that identify major cell classes present at earlier stages of development. These markers have allowed us to identify and follow particular cell types through development and have provided information about the mechanisms of cellular proliferation, neuronal migration, and axonal navigation and maturation in the developing mammalian nervous system.

\section{Cellular proliferation}

During cellular proliferation in the neural tube, a group of morphologically homogeneous cells gives rise to a variety of cell types and neural structures. One of the monoclonal antibodies we generated against the E15 ral spinal cord, Rat-401, recognizes many of the cells in the neural tube at late E11. The Rat-401 antigen (a 200-kd species on immunoblots of SDS-polyacrylamide gels) first appears in the developing rat CNS after neural tube closure, on E11 (Fig. 5). The antigen is first found restricted to punctate areas along the pial surface. Later (late E 11/early E12), the antigen extends within cells from the ventricular to the pial surface and most, perhaps all, of the cells in the neural tube are antibody positive. As neural development proceeds, antibody-positive cells come to resemble the radial glial cells described by Ramón y Cajal (1929) and antibody-negative cells become apparent (Figs. $1 B$ and $6 A$ ). Electron microscopic immunocytochemistry has shown that the antibody recognizes mitotic cells (Fig. 6B). Our studies of dissociated cells have shown that greater than $98 \%$ of the cells in the late E11 neural tube are Rat401 positive (Frederikson et al., 1985). These results show, at the limit of resolution of our current techniques, that most of the cells in the early neural tube share a common antigen that later is expressed by a specific subpopulation of cells, the radial glial cells, suggesting that a common Rat-401-positive progenitor cell gives rise to both neurons and glia.

One possible explanation of cellular differentiation in the nervous system is that the earliest neuroepithelial cells are programmed to differentiate into specific adult cell types. An alternative explanation is that cellular differentiation occurs at a later stage, perhaps after the earliest cells already have begun to proliferate. One major choice of differentiation is that between becoming a neuron or a glial cell. Levitt et al. (1981) suggest that the population of neuroepithelial cells that will give rise to glial cells is distinct from the population that will give rise to neurons. Raff et al. (1983; and M. C. Raff, personal communication) suggest that, whereas progenitor cells are destined to give rise to specific cell types, the division between neurons and glia is not respected and one population of progenitor cells gives rise to some classes of glial cells and another population gives rise to other classes of glial cells and neurons. These observations of Levitt et al. (1981) and Raff et al. (1983), of two antigenically distinct populations of cells present at later developmental stages than the earliest stages reported here, may reflect differentiation events subsequent to the stage where the majority of cells express the Rat401 antigen. One simple interpretation of our result is that the predominant early cell class in the neural tube gives rise to both neurons and glia. Alternatively, the early neuroepithelial cells, although apparently homogeneous with respect to the Rat-401 antigen, may be inhomogeneous with respect to other antigens. Our ongoing studies of dissociated cells and of tissue sections using Rat-401 and other markers may more definitively demonstrate the developmental potential of early neuroepithelial cells.

\section{Neuronal migration}

Neurons generated at the ventricular surface of the neural tube must migrate to their adult positions. Simple explanations of earlyborn cells being pushed along by later-born cells are insufficent since, often, the path along which a neuron migrates is circuitous and different from the obvious orientation of other cells and processes in the immediate environment. Another cell, the radial glial cell, has been postulated to provide a substrate upon which neurons migrate (Rakic, 1971). Neurons have been shown to migrate on non-neuronal cells in vitro (Hatten et al., 1984).

Radial glial cells are specifically recognized by monoclonal antibody Rat-401 throughout the developing rat CNS. Unlike other markers for radial glial cells, anti-GFAP in primates (Levitt and Rakic, 1980) and anti-vimentin in rodents (Dahl et al., 1981; Tapscott et al., 1981), antigens recognized by Rat-401, are restricted at late developmental stages to the radial glial cell and are not present in any other cell type in the embryonic or adult CNS (Figs. 4 and 7). In the adult, GFAP is present in glial cells. Vimentin is present in ependymal cells and tanycytes, which in some regions of the adult CNS span ventricular to pial surfaces like the early radial glial cells. Rat-401, therefore, has allowed us to study the in vivo developmental changes of radial glial cells in the absence of other antibody-positive elements.

Rat-401 recognizes radial cells throughout the developing rat brain 

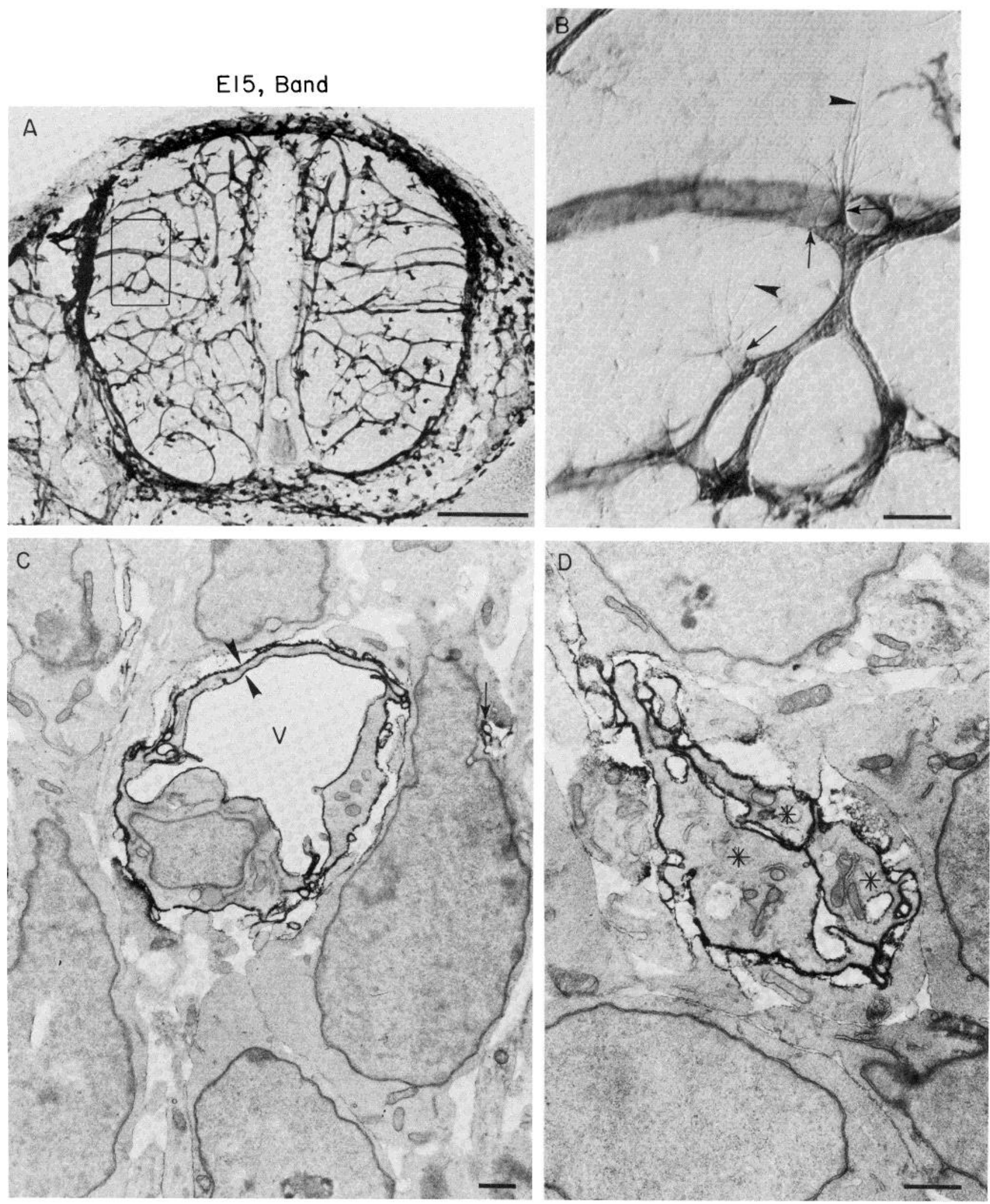

Figure 14. Lectins from Bandeiria simplicofolia (Band) recognize the developing vascular system. A, At E15 many blood vessels are present in the neural tube and are recognized by BAND. Bar $=500 \mu \mathrm{m}$. B. Higher magnification of the boxed area in $A$ shows nodes, or peaks (arrows) along the surface of established vessels giving rise to numerous fine processes (arrowheads) that contact one another. Bar $=50 \mu \mathrm{m}$. $C$, Electron micrograph shows that the lectin binds to both luminal and abluminal surfaces (arrowheads) of endothelial cells that form a patent blood vessel (V). Several fine processes in contact with one another are shown at the arrow. Bar $=1 \mu \mathrm{m}$. D. Three cell processes (asterisks) in contact with one another have not yet formed the lumen of a bood vessel. Bar $=1 \mu \mathrm{m}$. 
but in no area of the adult rat brain. We have examined the time course of the loss of the Rat-401 antigen and shown that antigen loss correlates with the end of the period of neuronal proliferation and migration (Fig. 7). Rat-401, therefore, recognizes a cell that is temporally and spatially suited to guide neuronal migration. The adult rat spinal cord contains no cell with a radial morphology, suggesting that the loss of the Rat-401 antigen reflects the loss of the cell class that expresses Rat-401. in the cerebellum and retina it is not as clear cut that the Rat-401-positive radial cells are lost, as radial cells in the adult cerebellum and retina are morphologically similar to the early radial cells identified with Rat-401. Ncither the corcbcllar Bergmann glia nor the retinal Müller cells are Rat-401 positive, but both are positive with antibodies to GFAP. These results raise the possibility that there may be two populations of radial cells in the rat, an early Rat-401-positive cell and a late GFAP-positive cell. Two other observations are consistent with this possibility. First, in primary cultures of developing cerebellar cells we have found that most cells express only one of these antigens. Only a very small number of cells express both the Rat-401 antigen and GFAP (unpublished results), suggesting that Rat-401 cells may give rise to GFAP-positive cells later in development. Second, $\left[{ }^{3} \mathrm{H}\right]$ thymidine studies have shown that the Bergmann glia are generated as late as the second postnatal week (Das et al., 1974). Rat-401-positive cells are not seen in the cerebellum after day 21, suggesting that an early period of cellular proliferation gives rise to Rat-401-positive radial glial cells and a later period of proliferation to GFAP-positive Bergmann glia. Our results show that the Bergmann glial cell and the early Rat-401 radial cell are antigenically distinct. Further studies of the developmental and functional relationships between these different classes of radial cells and of the relationships between Rat-401-positive cells and migrating neurons in vitro and in vivo are necessary to determine whether the Rat-401-positive radial glial cell is a transient cell type with the specific function of guiding migrating neurons.

\section{Axonal navigation}

Rat-202 recognizes early axons and growth cones. Many studies have shown that axons choose particular routes along which to grow and make contacts with specific targets. The mechanisms that guide axonal growth are not well understood, but chemoaffinity hypotheses (Ramón y Cajal, 1929; Sperry, 1943) postulate that chemical differences among axons mediate route and target specificity. We have previously shown that developing axons carry surface molecular differences (McKay et al., 1983), as predicted by chemoaffinity hypotheses. The growth cone, the terminal enlargement of a growing axon, and the fine filopodia that arise from the growth cone are thought to lead the growth of an axon along its route. The ability to visualize growing axons including the growth cone and filopodia would allow one to follow early axon routes and to determine the structures axons contact. Silver staining methods (Windle and Baxter, 1936), electron microscopy (Vaughn and Grieshaber, 1973), and filling cells with HRP (Lance-Jones and Landmeser, 1980) have been used to study early axons, but each of these methods has limitations. Silver methods are somewhat inconsistent and are not well suited for electron microscopic analysis; electron microscopy alone does not allow one to rapidly sample large areas of tissue; and filling axons with HRP requires that early phases of axon development have already taken place. Monoclonal antibody Rat202 recognizes early axons, their growth cones, and filopodia in the developing rat nervous system. We have used Rat-202 to study features of axonal development inaccessible by previously available techniques.

Early axons have been observed in the rat spinal cord at $E 12$ by electron microscopic (Vaughn and Grieshaber, 1973) and silver (Windle and Baster, 1936) methods. Rat-202 detects many axons throughout the E12 animal (Fig. 6, C and D). Development in the rat neural tube occurs over a rostrocaudal gradient where rostral cervical levels are more advanced than more caudal levels. We have been able to perform relatively rapidly a light microscopic serial section analysis of E10 to E20 rats to observe the development of axons identified with Rat-202 and of non-neuronal cells identified with Rat401. Using Rat-202 we have identified axons at rostral cervical levels of E11 embryos (Fig. 8, $A$ and $B$ ) but not at more caudal levels. As axons grow into the periphery from E11 onward, Rat-202 stains their growth cones and filopodia as they contact other axons to form fascicles (Fig. 8D) and as they begin to innervate peripheral structures (Fig. 9). Antibody Rat-202 appears to recognize early axons with at least the sensitivity of other available techniques and provides a means to identify growth cones and filopodia.

In contrast to the periphery, studying axon development in the mammalian CNS is further hampered by the difficulty of discriminating axons and growth comes from other neural elements. Rat-202 enables us to visualize early axons in the CNS, and we have now described two types of growth cones in the developing dorsal horn (Fig. 10). At the electron microscopic level, CNS growth cones contain vesicles and the filopodia arising from the growth cones contact profiles unstained by Rat-202 (Fig. 10E). These studies show that antibody Rat-202 provides a positive marker to follow early events in axon outgrowth at the light and electron microscopic levels.

Early axons contact a non-neuronal cell that precedes axons in the ventral root. In addition to the radial glial cells in the CNS, monoclonal antibody Rat-401 recognizes peripheral cells in several locations including the ventral roots and peripheral nerves (Fig. 6). Rat-401-positive processes occupy the position of ventral roots before axons have grown into the ventral root, as determined by staining serial sections with Rat-202 and by electron microscopic inspection. At later stages when axons are present, electron microscopic studies show that non-neuronal Rat-401-positive processes are often in direct contact with axons and that Rat-202-positive axons are in direct contact with non-neuronal cells (Fig. 11). Rat401-positive processes precede axons in the ventral roots and predict axon pathways into the periphery. Studies on amphibia (Nordlander et al., 1981) have also suggested that axons first grow into the periphery on a non-neuronal cell. In vitro studies of axon growth (Adler and Varon, 1981; Bunge et al., 1982) are compatible with the hypothesis that axons initially grow on a non-neuronal cell. Our observations suggest that in mammals a non-neuronal, Rat-401positive cell may play an important role in guiding axons from the CNS to the periphery. Experiments in progress suggest that the Rat401-positive cells that precede axons in peripheral nerves are early Schwann cells (Friedman and Hockfield, 1985).

The work of Aguayo et al. (1982) on CNS regeneration implicates a peripheral, non-neuronal cell as the source of factors "permissive" for axonal regeneration. One interesting possibility raised by the distribution of Rat-401-positive cells is that the Rat-401 antibody marks a cell type competent to support axon regeneration.

A group of peripheral and central non-neuronal cells similar to the group recognized by Rat-401 has been reported to carry other common antigens, vimentin (Tapscott et al. 1981), and the antigen recognized by monoclonal antibody C3/1 (Wakshull et al., 1983). We have shown by several criteria that the Rat-401 antigen is distinct from vimentin. Monoclonal antibody $\mathrm{C} 3 / 1$ recognizes a surface antigen with an apparent $M_{r}=38,000$ and, therefore, also is distinct from the antigen recognized by Rat-401. The fact that cells with quite distinct locations and morphologies share three antigens suggests that these apparently different cell types might share a common derivation and/or function, and that antigenically related cell types in the peripheral and central nervous system may guide axon elongation and neuronal migration.

\section{Axonal maturation}

We have shown here that different stages in axonal maturation are marked by the expression of different antigens. Adult axons are recognized by three different monoclonal antibodies, Rat-202, Cat101, and Cat-201. Each of these antibodies first recognizes axons at different times during development. In the rat, Rat-202 appears to 
recognize axons at the earliest stages of axon outgrowth at E11; Cat-101 first recognized axons at E17; and Cat-201 first recognizes axons in the third postnatal week. The differences in staining do not reflect differences in axon populations as we have shown that axons are present and recognized by Rat-202 in the corticospinal tract and dorsolateral funiculus before they are recognized by either Cat-101 or Cat-201. The molecular weights and subcellular localization of antigens recognized by Cat-101 and Cat-201 suggest that both antibodies may recognize the $210-\mathrm{kd}$ neurofilament subunit. Other studies have shown that the 210-kd neurofilament protein is expressed late in development, after the lower molecular weight species (Shaw and Weber, 1982; Baitinger et al., 1983). We have not yet determined whether the histological and temporal differences between Cat-101 and Cat-201 staining reflect post-translational modifications of a single gene product (Sternberger and Sternberger, 1983) or reflect different gene products. In any case, the present study shows that differences in immunoreactivity can be used to mark developmental changes within a population of axons. Anatomical studies have suggested that there are distinct phases in axon growth (Rakic, 1976; Dennis et al., 1981; Jones et al., 1982). For cxample, axons whose targets are in the cortex appear to wait below the cortical plate for a signal to grow further to their final destination. An important potential use of antigens which distinguish biochemical phases in neuronal differentiation is as a molecular assay which may allow us to more accurately define developmental events in axon maturation both in vivo and in vitro.

\section{The developing vascular system}

Precursors to the endothelial cells of the vascular system are first seen in the neural tube on E12. These cells appear to invade the neural tube from a series of defined points along the perimeter of the tube. They then proliferate and form the vascular system by extending processes which fasciculate and then form a lumen within the fascicie. The presence of vascular endothelial cell precursors in the nerve cord may influence the proliferation and differentiation of neural cells. One interesting possibility is that the invading endothelial cells may secrete growth factors which promote neuroepithelial cell proliferation. Large aortic endothelial cells, when grown in culture, secrete platelet-derived growth factor (PDGF) (DiCorleto and BowenPope, 1983). PDGF has been purified using glial cell proliferation as an assay (Westermark and Wasteson, 1976). ^ related factor can be purified from bovine brain (Lemke and Brockes, 1984) and has been shown to promote glial cell proliferation. The influence of endothelial cells on neuronal and glial development has not yet been established, but having a marker for these cells distinct from other cell types will provide an important tool in the analysis of these interactions.

\section{References}

Adler, R., and S. Varon (1981) Neuritic guidance by non-neuronal cells of ganglionic origin. Dov. Biol. 86: 69 80 .

Aguayo, A. J., P. M. Richardson, S. David, and M. Benfey (1982) Transplantation of neurons and sheath cells-a tool for the study of regeneration. In Repair and Regeneration of the Nervous System, J. G. Nicholls, ed., pp. 91-105, Springer-Verlag. New York.

Altman, J. (1972) Postnatal development of the cerebellar cortex in the rat III. Maturation of the components of the granular layer. J. Comp. Neurol 145: 465-514.

Baitinger, C., R. Cheney, D. Clements, M. Glicksman, N. Hirokawa, J. Levine, K. Meiri, C. Simon, P. Skene, and M. Willard (1983) Axonally transported proteins in axon development, maintenance, and regeneration. Cold Spring Harbor Symp. Ouant. Biol. 48: 791-802.

Barald, K. F. (1982) Monoclonal antibodies to embryonic neurons: Cell specific markers for ciliary ganglia. In Neuronal Development, N. C. Spitzer, ed., pp. 101-119, Plenum Press, New York.

Bunge, M. B., A. K. Williams, and P. K. Wood (1982) Neuron-Schwann cell interaction in basal lamina formation. Dev. Biol. 92: 449-460.

Dahl, D., D. Rueger and A. Bignami (1981) Vimentin, the 57,000 molecular weight protein of fibroblast filaments, is the major cytoskeletal component in immature glia. Eur. J. Cell Biol. 24: 191-196.
Das, G. D., G. L. Lanmert, and J. P. McAllister (1974) Contact guidance and migratory cells in the developing cerebellum. Brain Res. 69: 13-20.

DiCorleto, T. E., and D. S. Bowen-Pope (1983) Cultured endothelial cells produce a PDGF-like protein. Proc. Natl. Acad. Sci. U. S. A. 80: 19191923.

Dennis, M. J., L. Ziskind-Conhaim, and A. J. Harrıs (1981) Uevelopment or neuromuscular junctions in cat embryos. Dev. Biol. 81: 266-279.

Frederikson, K., R. McKay, and S. Hockfield (1985) The differentiation of radial glial cells. Soc. Neurosci. Abstr. 11: 807.

Freidman, B., and S. Hockfield (1985) Monoclonal antibody Rat-401 identifies developing Schwann cells. Soc. Neurosci. Abstr. 11: 986.

Hatten, M. E., R. K. Liem, and C. A. Mason (1984) Two forms of cerebellar glial cells interact differently with neurons in vitro. J. Cell Biol. 98: 193204.

Hawkes, R., E. Niday, and A. Matus (1982) Monoclonal antibodies identify novel neural antigens. Proc. Natl. Acad. Sci. U. S. A. 79: 2410-2414.

Hockfield, S., R. D. G. McKay, S. H. C. Hendry, and E. G. Jones (1983) A surface antigen that identifies ocular dominance columns in the visual cortex and laminar features of the lateral geniculate nucleus. Cold Spring Harbor Symp. Quant. Biol. 48: 877-889.

Jones, E. G., D. J. Schreyer, and S. P. Wise (1982) Growth and maturation of the rat corticospinal tract. Prog. Brain Res. 57: 361-379.

Lance-Jones, C., and L. Landmesser (1980) Motoneuronal projection patterns in embryonic chick limbs following partial deletions of the spinal cord. J. Physiol. (Lond.) 302: 559-580.

Le Douarin, N. M. (1980) The ontogeny of the neural crest in avian embryo chimeras. Nature 286: 663-669.

Lemke, G. E., and J. P. Brockes (1984) Identification and purification of glial growth factor. J. Neurosci. 4: 75-83.

Levitt, P. (1984). A monocional antibody to limbic system neurons. Science 223: 299-301.

Levitt, P., and P. Rakic (1980) Immunoperoxidase localization of glial fibrillary acidic protein in radial glial cells and astrocytes of the developing rhesus monkey brain. J. Comp. Neurol. 193: 815-840.

Levitt, P., M. L. Cooper and P. Rakic (1981) Coexistence of neuronal and glial precursor cells in the cerebral ventricular zone of the fetal monkey: An ultrastructural immunoperoxidase analysis. J. Neurosci. 1: 27-39.

McKay, R. D. G., and S. Hockfield (1982) Monoclonal antibodies distinguish antigenically discrete neuronal types in vertebrate central nervous system. Proc. Natl. Acad. Sci. U. S. A. 79: 6747-6751

McKay, R. D. G., S. Hockfield, J. Johansen, I. Thompson, and K. Frederikson (1983) Surface molecules identify groups of growing axons. Science 222 788-794.

Nordlander, R. H., J. F. Singer, R. Beck, and M. Singer (1981) An ultrastructural examination of early ventral root formation in amphibia. J. Comp. Neurol. 199: 535-551.

Nornes, H. O., and G. D. Das (1974) Temporal pattern of neurogenesis in spinal cord of rat. I. An autoradiographic study-time and sites of origin and migration and settling patterns of neuroblasts. Brain Res. 73: 121138.

Ouchterlony, Ö., and C. A. Nilsson (1978) Immunodiffusion and immunoelectrophoresis. In Handbook of Experimental Immunology, D. M. Weir, ed., Blackwell Scientific Publications, Oxford.

Pruss, R. M., R. Mirsky, M. C. Raff, R. Thorpe, A. J. Dowding, and B. H. Anderton (1981) All classes of intermediate filaments share a common antigenic determinant defined by a monoclonal antibody. Cell 27: 419428.

Raff, M. C., R. H. Miller, and M. Noble (1983) A glial progenitor cell that develops in vitro into an astrocyte or an oligodendrocyte depending on the culture medium. Nature 303: 390-396.

Rakic, P. (1971) Neuron-glia relationship during granule cell migration in developing cerebellar cortex. A Golgi and electronmicroscopic study in Macacus rhesus. J. Comp. Neurol. 141: 283-312.

Rakic, P. (1976) Prenatal genesis of connections subserving ocular dominance in the rhesus monkey. Nature 261: 467-471.

Ramón y Cajal, S. (1929) Studies on Vertebrate Neurogenesis, I. Guth, transl., Charles $C$ Thomas, Springfield, IL.

Shaw, G., and K. Weber (1982) Differential expression of neurofilament triplet proteins in brain development. Nature 298: 277-279.

Sidman, R. L. (1970) Cell proliferation, migration and interaction in the developing mammalian central nervous system. In The Neurosciences. Second Study Program, F. O. Schnitt, ed., pp. 100-116, Rockefeller University Press, New York.

Spemann, II. (1936) Embryonic Development and Induction, Hafner Press, New York.

Sperry, R. W. (1943) Chemoaffinity in the orderly growth of nerve fiber 
patterns and connections. Proc. Natl. Acad. Sci. U. S. A. 50: 703-710.

Sternberger, L., and N. Sternberger (1983) Monoclonal antibodies distinguish phosphorylated and nonphosphorylated forms of neurofilaments in situ. Proc. Natl. Acad. Sci. U. S. A. 80:6126-6130.

Sternberger, L. A., L. W. Harwell, and N. H. Sternberger (1982) Neurotypy: Regional individuality in rat brain detected by immunocytochemistry with monoclonal antibodies. Proc. Natl. Acad. Sci. U. S. A. 79: 1326-1330.

Tapscott, S., G. Bennett, Y. Toyama, F. Kleinbart, and H. Holtzer (1981) Intermediate filament proteins in developing chick spinal cord. Dev. Biol. 86: $40-54$.

Towbin, H., T. Staehelin, and J. Gordon (1979) Electrophoretic transfer of proteins from polyacrylamide gels to nitrocellulose sheets: Procedure and some applications. Proc. Natl. Acad. Sci. U. S. A. 76: 4350-454.

Vaughn, J. E., and J. A. Grieshaber (1973) A morphological investigation of an early reflex pathway in developing rat spinal cord. J. Comp. Neurol.
148: $177-210$

Vincent, M., and J. P. Thiery (1984) A cell surface marker for neural crest and placodal cells: Further evolution in peripheral and central nervous systcm. Dcv. Biol. 103: 468481

Wakshull, E., E. K. Bayne, M. Chiquet, and D. M. Fambrough (1983) Characterization of a plasma membrane glycoprotein common to myoblasts, skeletal muscle satellite cells and glia. Dev. Biol. 100: 464-477.

Westermark, B., and A. Wasteson (1976) A platelet factor stimulating normal human glial cells. Exp. Cell Res. 98: 170-174.

Windle, W. F., and R. F. Baxter (1936) Development of reflex mechanisms in the spinal cord of albino rat embryos. Correlations between structure and function, and comparisons with the cat and the chick. J. Comp. Neurol. 63: 189-209.

Zipser, B., and R. D. G. McKay (1981) Monoclonal antibodies distinguish identifiable neurons in the leech. Nature 289: 549-554. 